\title{
A STUDY ON TENSILE FORCE MANAGEMENT METHOD FOR ADDITIONAL GROUND ANCHOR CONSTRUCTION IMPLEMENTED AS A DETERIORATION COUNTERMEASURE
}

\author{
Yu FUJIWARA ${ }^{1}$, Toyokazu MURAKAMI², Mutsutoshi FUKUDA³, \\ Makoto TAKASHIMA ${ }^{4}$ and Hirotaka NAGAKI ${ }^{5}$ \\ ${ }^{1}$ Member of JSCE, Assistant Manager, Technical Management Manager Technical Development and Environment \\ Department Technical Development Bureau, West Nippon Expressway Company Limited \\ (1-6-20 Dojima Kita-ku, Osaka 530-0003, Japan) \\ E-mail: y.fujiwara.ae@w-nexco.co.jp \\ ${ }^{2}$ Member of JSCE, Chief, Geotechnics Division Road Research Department, Nippon Expressway Research Institute \\ Company Limited (1-6-20 Tadao, Machida-shi, Tokyo 194-8508, Japan) \\ E-mail: t.murakami.ae@w-nexco.co.jp \\ ${ }^{3}$ Non-member of JSCE, Chief Engineer, Japan Conservation Engineers Company Limited \\ (2-1-30 Hamabe Dori, Chuo-ku, Kobe, Hyogo 651-0083, Japan) \\ E-mail: m-fukuda@jce.co.jp \\ ${ }^{4}$ Non-member of JSCE, Branch Manager, Japan Conservation Engineers Company Limited \\ (2-8-36 Arito, Suruga-ku, Shizuoka-shi, Shizuoka 422-8032, Japan) \\ E-mail: takashima@jce.co.jp \\ ${ }^{5}$ Non-member of JSCE, Assistant Manager, Sansui navico \\ (2-7-1 Nihonbashi Kayabacho, Chuo-ku, Tokyo 103-0025, Japan) \\ E-mail: h.nagaki@snse.co.jp
}

\begin{abstract}
The anticorrosion functions of ground anchors (hereinafter anchors) have been strengthened after the revision of standards by the former Japanese Society of Soil Mechanics and Foundation Engineering (present Japanese Geotechnical Society) in 1988. However, some old-type anchors constructed before the revision have failed to achieve the prescribed function due to corrosion of steel materials. Therefore, the three NEXCO companies have indicated in their expressway policy that they will install a new type of anchor in the specific renewal and other works, which were approved in 2016. In installing additional anchors as a measure to supplement existing old anchors, some issues remain. For example, there is no concrete method developed to manage the tensile force when unloading tensile force of existing anchors. This paper examines the handling of existing anchors at the sites where special anchor renewal works were carried out and, based on the findings, proposes a tensile force management method to be used in countermeasures for anchor deterioration.
\end{abstract}

Key Words : ground anchor, tension management, cut slope, strain gauge, residual tensile load

\section{INTRODUCTION}

Expressways managed by the three NEXCO companies (hereinafter expressways) have been in service more than 50 years, and it is becoming difficult to maintain their health over a long period of time through conventional maintenance and repair methods $^{1)}$. Against this backdrop, the three NEXCO companies received approval from the Japanese Minister of Land, Infrastructure, Transport and Tourism in March 2015 to carry out an expressway renewal project ${ }^{2}$ for a term of 15 years at 3 trillion 6.4 billion yen based on the proposal ${ }^{3)}$ by the "Technical Review Committee on Long-term Maintenance and Renewal of Expressway Assets".

The purpose of an expressway renewal project for earthwork structures is to improve long-term durability of embankment slopes, cut slopes, and drainage facilities. For cut slopes, ground anchors (hereinafter anchors) will be improved. Measures ${ }^{4)}$ will be taken mainly on old-type anchors, which were installed before anticorrosion functions were strengthened, when standards were amended by the then Japanese Society of Soil Mechanics and Foundation Engineering 
(current Japanese Geotechnical Society), in 1988, that have lost specific functions due to corrosion of steel, like the anchor shown in Fig.1.

When dealing with aging anchors in an expressway renewal project, renewal works are carried out systematically, taking into account the priority of anchors that need to be renewed. Of all the expressways operated by NEXCO, expressways in the area managed by NEXCO West has the largest number of oldtype anchors, and renewal works have started ahead of expressways managed by NEXCO East and NEXCO Central. The anchor renewal works were first conducted on the slopes of Okinawa Expressway and is currently underway on the slopes of Nagasaki Expressway and Yonago Expressway ${ }^{4), 5)}$.

Since anchors are installed on heterogeneous grounds, changes in the tension of anchors vary in relation to the type of ground they are constructed in and the level of landslide activity. And it is thought that slopes stabilize as tensions of each anchor change in different ways and, over time, converge to a certain state ${ }^{6), 7)}$. Figure 2 shows an example of the tension distribution, drawn by determining the ratio of the residual tensile force to the design anchor force, based on the results of a survey on the tension force of multiple anchors. Anchor tension is not uniform, and it is extremely difficult to predict the variation in advance. As a measure against anchor deterioration, attention should be paid to the state of tension of existing anchors, and if there is a tendency towards overtension, measures such as re-evaluation of the slip surface and the range of anchor installation are required.

Additional anchors are to be constructed in the vicinity of existing anchors as shown in Fig. $\mathbf{3}^{8)}$. In the stability assessment of the slope, the deterrence force of the existing anchors is basically not considered, and the additional anchors will perform the deterrence function after construction. However, since it is difficult to completely remove existing anchors, the tension of existing anchors remains. Unloading the tension of existing anchors may be considered as an option to reduce the burden on maintenance. But unloading may affect the stability of the slope and careful monitoring is required during construction ${ }^{4}$.

In this study, we planned the unloading of existing anchors in an area slated for an expressway renewal project. we also evaluated the effects of unloading the existing anchors have on anchors by analyzing the measured tensions of existing and additional anchors. In this paper, Chapter 2 presents the challenges countermeasures for anchor deterioration face, Chapter 3 describes anchor tension monitoring plans; Chapter 4 describes anchor tension measurement methods; Chapter 5 gives the considerations and observations of the study, and in Chapter 6 we propose a tension

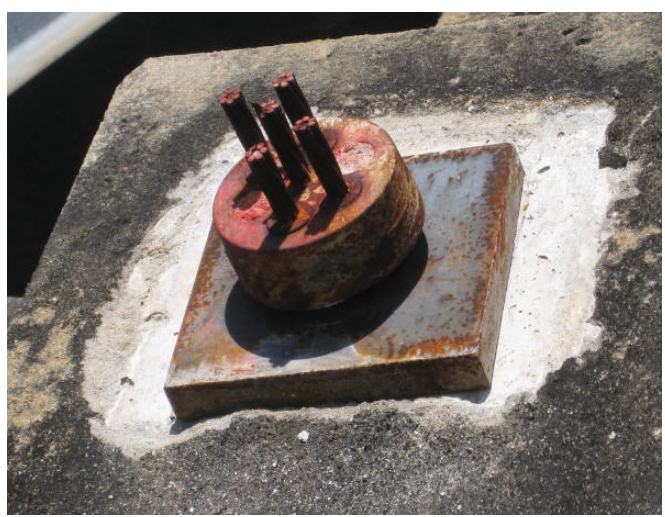

Fig.1 Anchor degraded by corrosion ${ }^{4}$.
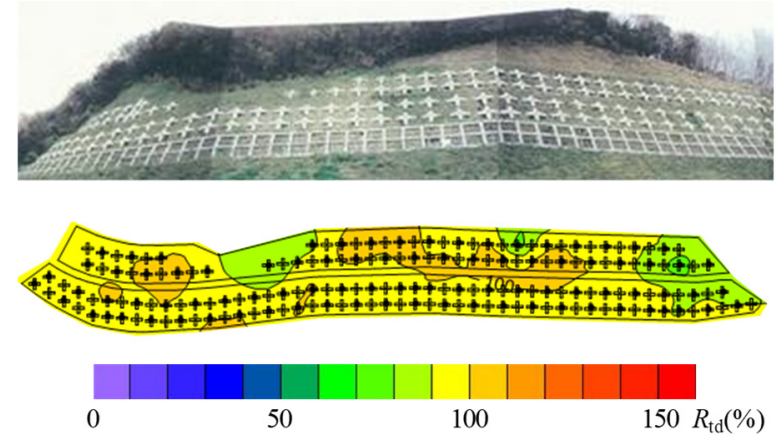

$R_{\mathrm{td}}:$ Ratio of residual tensile force to design anchor force (\%) Fig.2 Anchor tension distribution ${ }^{6}$.

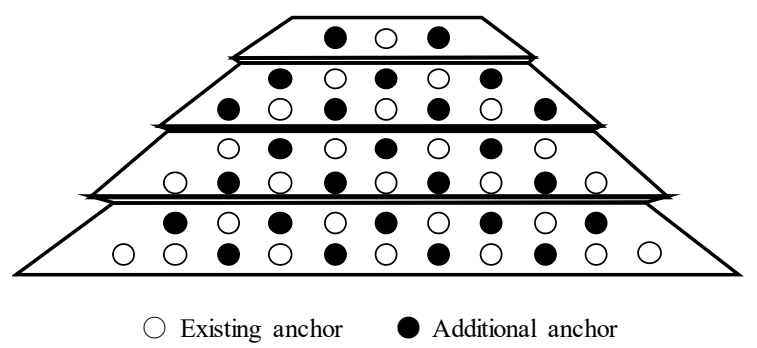

(Front view)

Fig.3 Front view of additional anchor placement (example) ${ }^{8)}$.

management method in the construction of additional anchors as an anchor deterioration countermeasure based on the knowledge gained from the study.

\section{CHALLENGES OF DETERIORATION COUNTERMEASURE FOR ANCHORS}

\section{(1) Management of anchor tension}

Measurements of anchor tension taken after the expressway goes into service become important data for judging slope stability. In this section, the management of anchor tension when anchors are constructed on expressways is described. In the construction stage, tension is controlled in $5 \%$ of the total number of anchors or at least five or more anchors ${ }^{8)}$.

The anchors whose tension will be controlled need to represent the tension of the entire slope, so the 


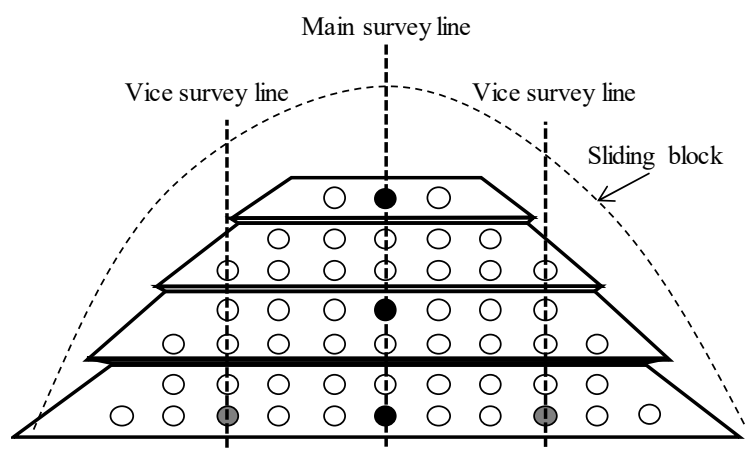

- Measurement points of anchor on main survey line Measurement points of anchor on vice survey lines Construction location of anchors

(Front view)

Fig.4 Example of anchor tension measurement ${ }^{8)}$.

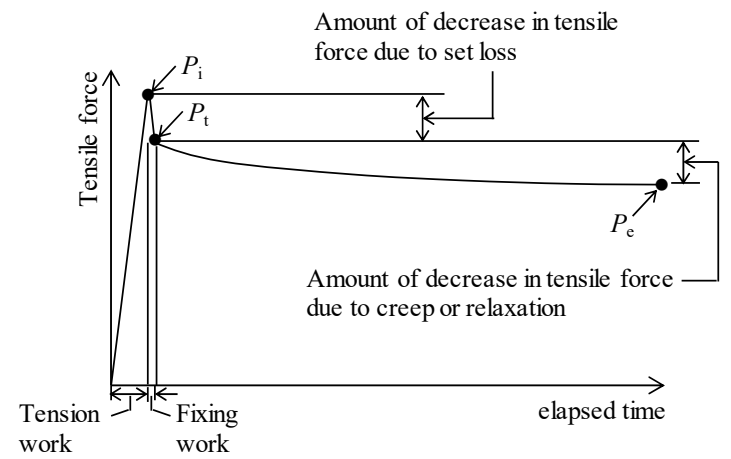

Fig.5 Conceptual diagram of changes in anchor tension over time ${ }^{9)}$

anchors will be selected from the main survey line and the vice survey line of the sliding block as shown in Fig. $4^{8)}$. A load meter is installed on the anchor at construction, and measurement is taken at least once a week. After the convergence of tension is confirmed, the measurements will be taken less frequently, and load meters and lift-off tests will be used to take measurements in the "Detailed Inspections."

On the other hand, as shown in the conceptual diagram Fig.5, the anchor tension generally decreases after tension is introduced at anchorage due to steel relaxation and back ground subsidence, and tends to approach a certain residual tensile force ${ }^{9)}$. Because the amount of decrease in tension varies from anchor to anchor, the tension may vary from anchor to anchor even when no external force is applied.

\section{(2) Handling of existing anchor}

In managing the tension of anchors, if the landslide activity does not converge even if a predetermined number of anchors are constructed, the slip surface may be revised as shown in Fig.6(a) and construction of additional anchors planned. On the other hand, as long as the slope is stable, the constructing of additional anchors aimed at combating the aging of existing anchors is planned based on the slip surface

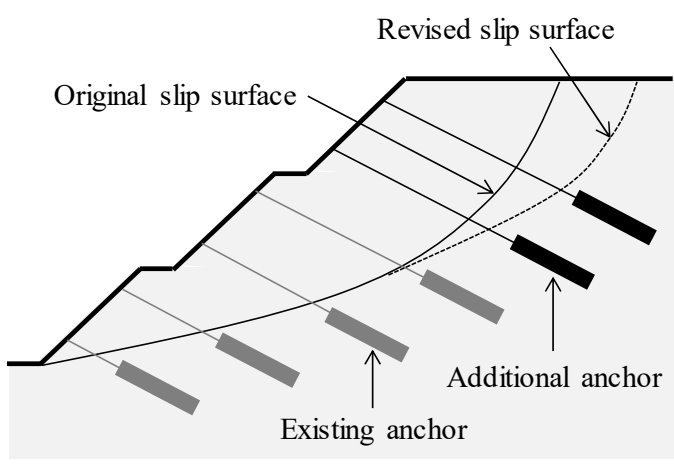

(Cross section)

(a) Revised slip surface

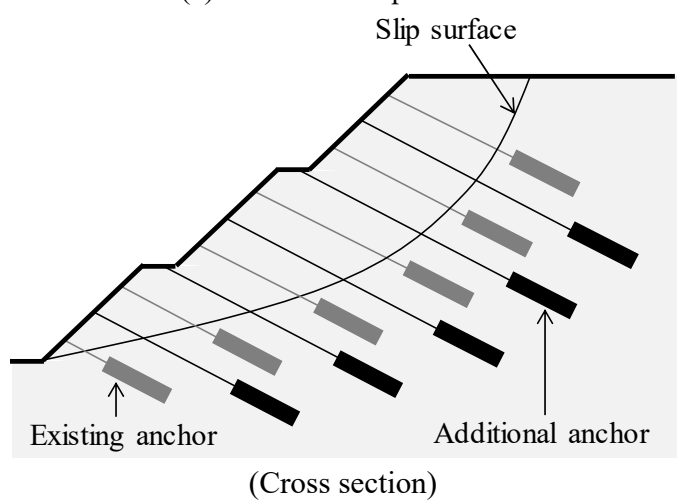

(b) Slip surface not revised

Fig.6 Example of additional anchor placement ${ }^{8)}$.

assumed at the time of design, and as shown in Fig.6(b), they are arranged considering the distance from existing anchors. In addition, when examining the stability of the slope, the deterrence force of the existing anchors is not basically considered, and the additional anchors are to perform the deterrence function after construction.

When dealing with the deterioration of anchors, it is necessary to consider how to handle the existing anchors. When installing anchors, holes are drilled and steel materials are embedded deep in the ground, so it is difficult to completely remove the existing anchors. Some existing steel bar-type anchors constructed on expressway slopes may pop out due to breakage, and preventive measures are taken on them, as shown in Fig. $\mathbf{7}^{4}$. After additional anchors are constructed as a deterioration countermeasure, the additional anchors will replace the existing anchors' deterrent function, but the tension of the existing anchors remain, so countermeasures such as the pop-out prevention measure may be considered. On the other hand, the burden on maintenance may be reduced by unloading the tension of the existing anchors. However, when unloading, it is necessary to monitor the influence of unloading on slope stability and carefully carry out the work. Regarding the handling of existing anchors when taking the measure against anchor deterioration, it is important to take appropriate measures considering future maintenance, based on 


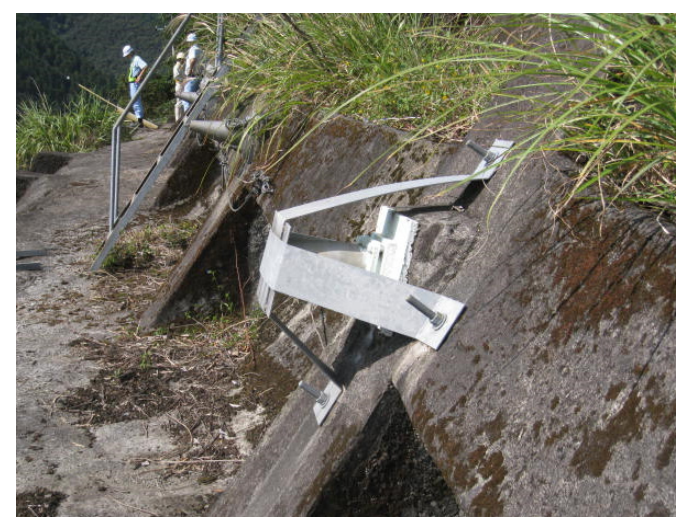

Fig.7 Anchor pop-out prevention measure ${ }^{4)}$.

the tension distribution of existing anchors and the distance between where the countermeasure was carried out and the expressway ${ }^{4}$.

\section{MONITORING PLAN OF ANCHOR TENSION}

\section{(1) Target slope}

The main symbols used in this paper are defined as follows ${ }^{6), 10)}$.

where $T_{\mathrm{ys}}$ : Tendon's yield tensile force

$T_{\mathrm{a}}$ : Allowable anchor force

$T_{\mathrm{d}}$ : Design anchor force

$P_{\mathrm{i}}$ : Initial tension

$P_{\mathrm{t}}$ : Tension at establishment

$P_{\mathrm{e}}$ : Residual tensile force (also called tension in this paper)

$T_{\mathrm{a}}$ : Planned maximum load

$l_{\mathrm{a}}:$ Anchor length

$l_{\mathrm{f}}:$ Anchor free length

$R_{\mathrm{td}}$ : Tensile strength remaining rate $\left(=P_{\mathrm{e}} / T_{\mathrm{d}}\right)$

$T:$ Outside temperature

$\varepsilon$ : Distortion

Figure 8 shows a slope of the Yonago Expressway where this study was carried out. Figure 9 shows the installation status of existing and additional anchors, Table 1 shows the structural specifications, and Fig.10 shows the structure of the anchor head. On this slope, 142 steel bar-type anchors were installed and covered entirely by spraying mortar. The anchors were placed as a measure against slip surface 1 that passes through the 5th to 11th stages and slip surface 2 that passes through the 10th to 11th stages.

As shown in Fig.10(a), the existing anchors are steel bar anchors ${ }^{11)}$ with a fully threaded PC steel bar fixed at the anchor head with a nut. Anchors installed at the 5 th to 9 th stages are $32 \mathrm{~mm}$ in diameter and the design anchor force is $374.1 \mathrm{kN} /$ anchor; the 10th and 11th stages are $26 \mathrm{~mm}$ in diameter, and the design

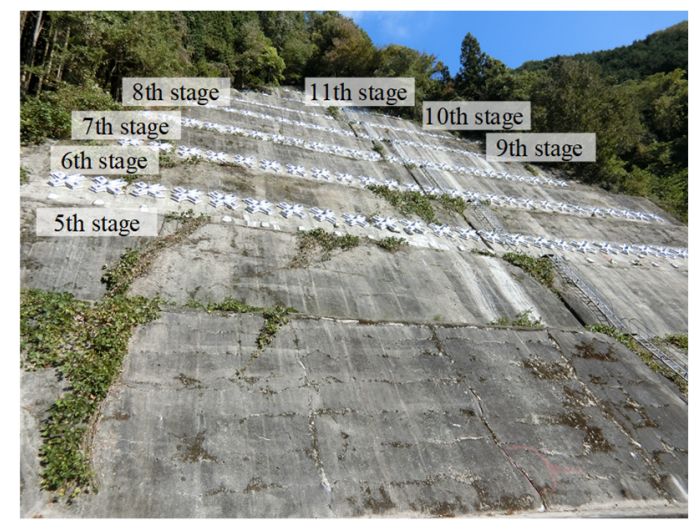

(a) Panoramic view ${ }^{5}$

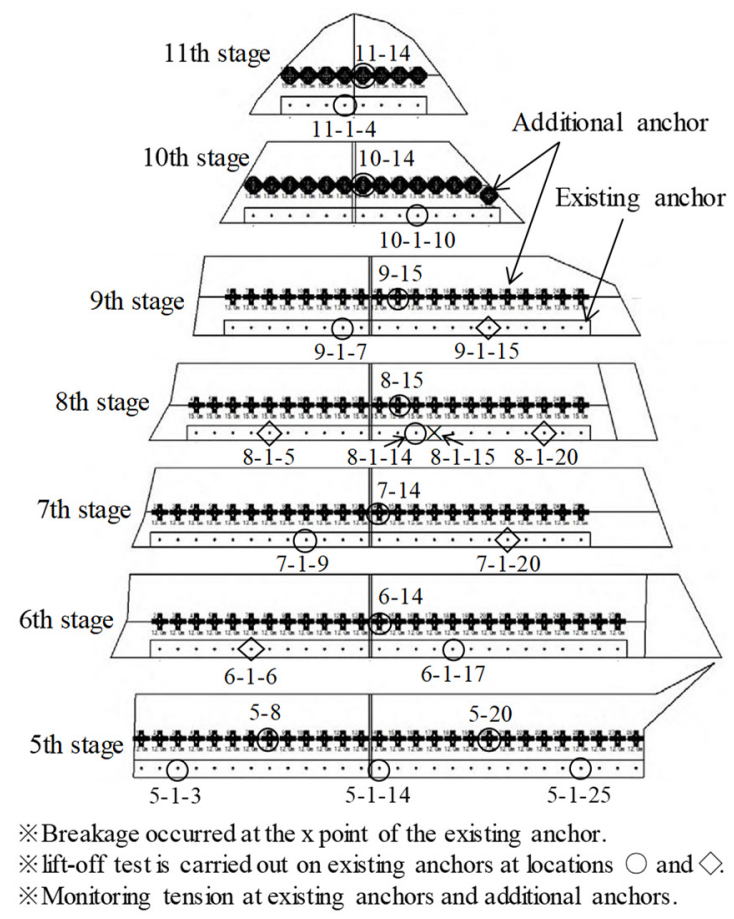

(b) Front view

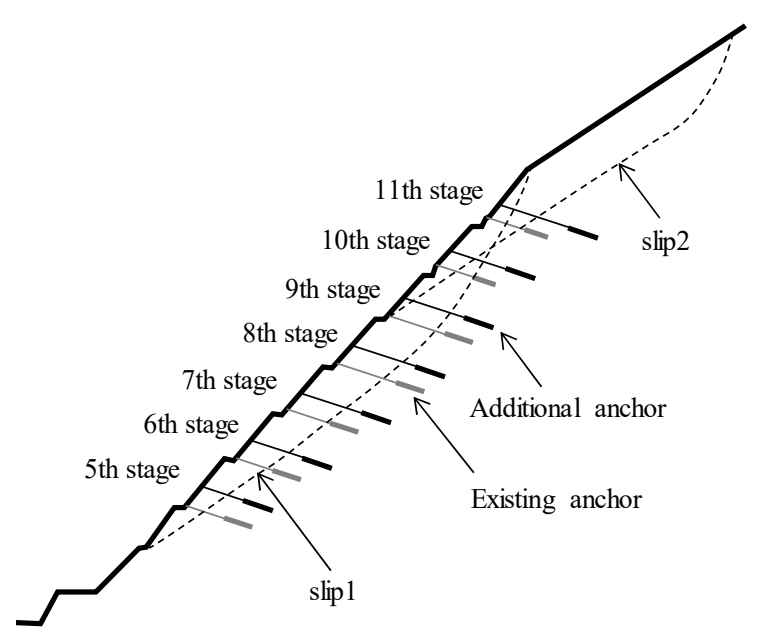

(c) Cross section

Fig.8 Anchor placement and tension measurement points.

anchor force is $316.1 \mathrm{kN} /$ anchor. The existing anchors are aging, and one anchor (No.8-1-15) has popped out due to breakage. 


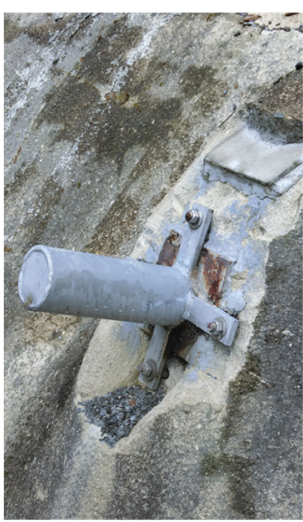

(a) Existing anchor

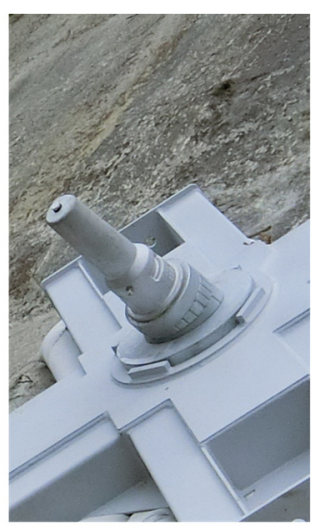

(b) Additional anchor
Fig.9 Anchor installation status.

Table 1 Anchor structure specifications. (a) Existing anchor

\begin{tabular}{c|c|c}
\hline item & 5th stage - 9th stage & 10th stage -11th stage \\
\hline type & $\begin{array}{c}\text { Fully threaded PC } \\
\text { steel bar (D32) }\end{array}$ & $\begin{array}{c}\text { Fully threaded PC } \\
\text { steel bar (D26) }\end{array}$ \\
\hline$T_{\mathrm{d}}$ & $374.1 \mathrm{kN}$ & $316.1 \mathrm{kN}$ \\
\hline$l_{\mathrm{a}}$ & $4.0 \mathrm{~m}$ & $3.5 \mathrm{~m}$ \\
\hline$l_{\mathrm{f}}$ & $5.0 \mathrm{~m}$ or more & $5.0 \mathrm{~m}$ or more \\
\hline
\end{tabular}

(b) Additional anchor

\begin{tabular}{c|c|c}
\hline item & 5th stage - 9th stage & 10th stage - 11th stage \\
\hline type & $\begin{array}{c}\text { Multiple strands } \\
\text { of PC steel }\end{array}$ & $\begin{array}{c}\text { Multiple strands } \\
\text { of PC steel }\end{array}$ \\
\hline$T_{\mathrm{d}}$ & $399.6 \mathrm{kN}$ & $732.2 \mathrm{kN}$ \\
\hline$l_{\mathrm{a}}$ & $4.5 \mathrm{~m}$ & $6.5 \mathrm{~m}$ \\
\hline$l_{\mathrm{f}}$ & $7.5 \mathrm{~m}-10.5 \mathrm{~m}$ & $6.5 \mathrm{~m}-9.5 \mathrm{~m}$ \\
\hline
\end{tabular}

On this slope, a pressure-receiving structure was built on the sprayed mortar, and 142 additional anchors, the same number as the existing anchors, were installed. As shown in Fig.10(b), the additional anchor is made of a multi-strand PC steel strand ${ }^{12)}$, in which multiple PC steel strands are twisted together and fixed with a nut at the anchor head. The design anchor force of the 5th to 9 th stages is $399.6 \mathrm{kN} / \mathrm{an}$ chor and the design anchor force of the 10th and 11th stages is $732.2 \mathrm{kN} /$ anchor. For slippage at the 10th and 11th stage, the existing anchors were planned to have an initial safety factor of 1.0 and a planned safety factor of 1.05 , but the additional anchors were designed to have a planned safety factor of 1.2 following current design standards. For this reason, the design anchor force is larger for the existing anchors than that for the additional anchors.

\section{(2) Study on unloading tension of existing anchors}

Existing anchors are steel-bar types that may pop out due to breakage. Considering the burden of maintenance in the future, studies were conducted with a view to unloading tension. When unloading

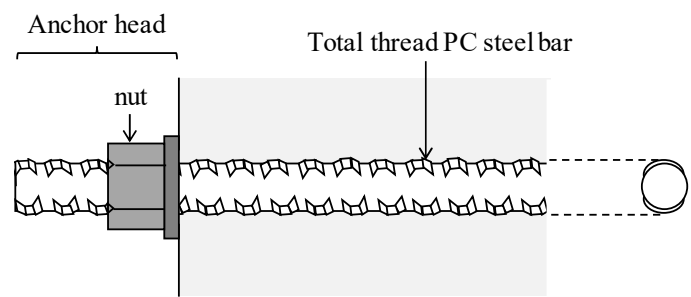

(a) Existing anchor

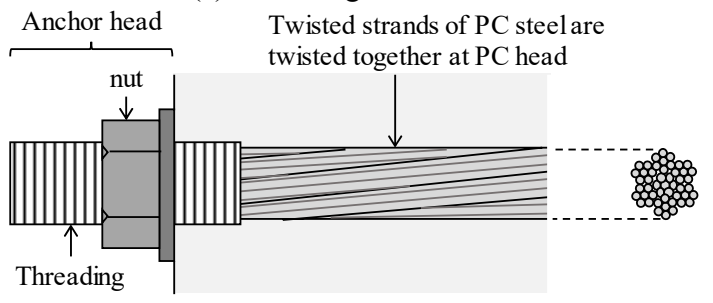

(b) Additional anchor

Fig.10 Anchor head structure ${ }^{11), 12)}$.

the tension of existing anchors in the construction of additional anchors as a deterioration countermeasure, monitoring the tension of not only the additional anchors but also that of the existing anchors will result in taking quick and appropriate measures for stabilization when the slope begins to destabilize. Since additional anchors are constructed in the vicinity of the existing anchors, it may be possible to unload existing anchors as additional anchor are constructed. However, since existing anchors are in a relatively high-tension state and the slope has seven stages and is long and steep, the effects of unloading tension on the stability of the slope were taken into account, and it was decided that whether the tension of existing anchors will be unloaded or not will be determined after installing all the additional anchors and confirming the changes in the tension of existing anchors. Therefore, the tension was measured not only for the additional anchors but also for the existing anchors.

Figure 11 shows the monitoring plan for tension from the construction of additional anchors to the unloading of the tension of existing anchors. First, liftoff tests are carried out on a portion of the existing anchors as indicated at No.1 in the flowchart. If the existing anchors are overtensioned overall, anchors are not unloaded following No.8, and measures to prevent existing anchors from popping out will be examined. On this slope, lift-off tests were conducted on 14 existing anchors (about 10\% of total) indicated in Fig.8(b) by the circle symbol and diamond symbol. The lift-off tests showed that on this slope the tension of existing anchors tended to be lower than the design anchor force as a whole and varied between $100 \mathrm{kN}$ and $400 \mathrm{kN}$. Therefore, it was judged that the tension of existing anchors could be unloaded following No.2, and the tension of existing anchors was monitored. Nine existing anchors were monitored (about $6 \%$ of total) that were subjected to lift-off tests. They are indicated with a circle in Fig.8(b). 


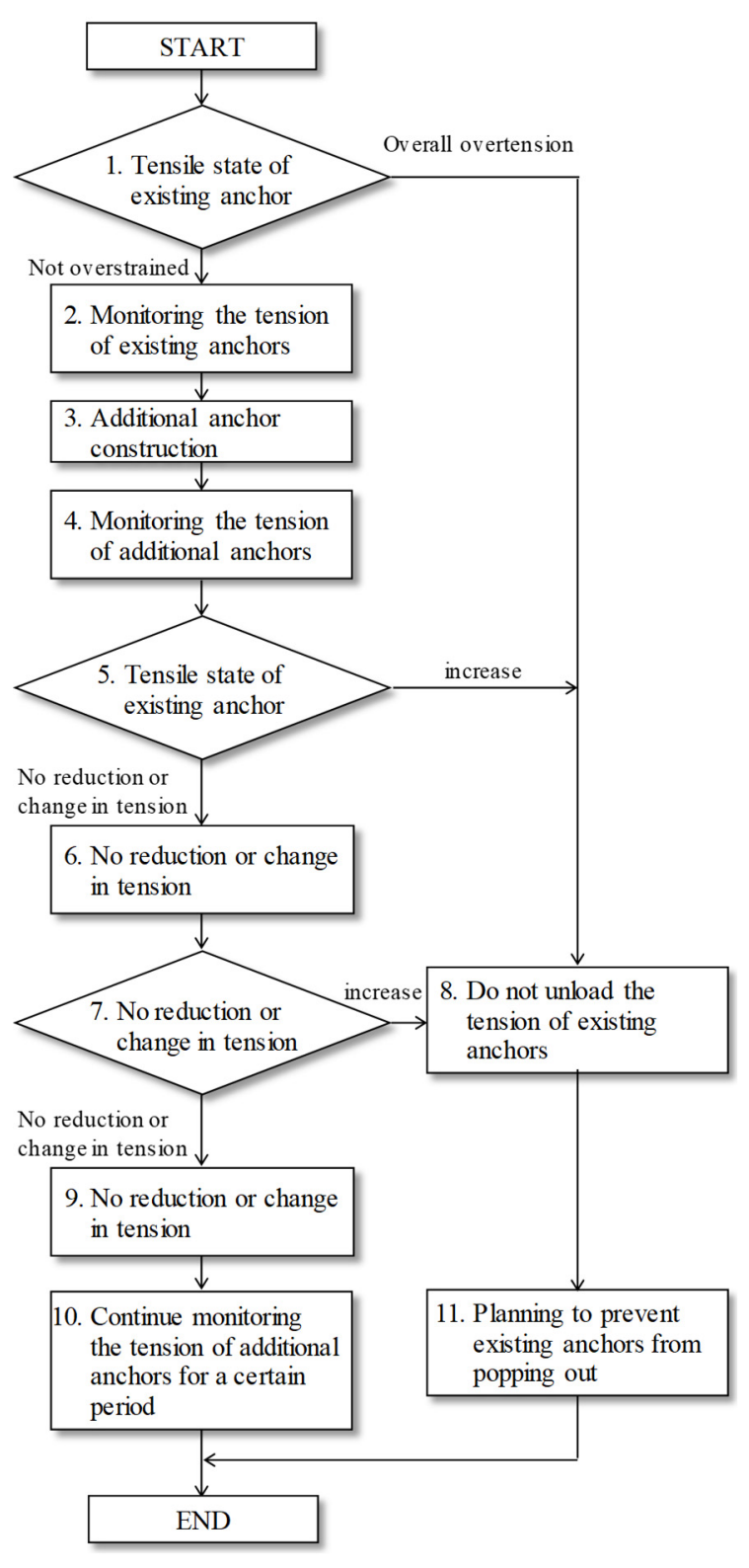

Fig.11 Anchor tension monitoring plan.

Next, additional anchors were constructed following No.3 and No.4 in the flowchart, and monitoring of tension started for eight additional anchors marked with a circle (approx. 6\% of total) in Fig.8 (b). At this time, after confirming that the tension of existing anchors did not increase, unloading of existing anchors started following No.5, No.6, and No.7. The work continued while confirming that the tension of the additional anchors did not increase during unloading. After all existing anchors were finally unloaded, the tension of the additional anchors was monitored for a certain period following No.10, and the effects of the unloading was confirmed. The number of anchors monitored was $5 \%$ of the total number of anchors or at least five or more anchors following the expressway construction management standard ${ }^{8}$.

\section{MEASUREMENT OF ANCHOR TEN- SION}

\section{(1) Measurement of tension of existing anchors}

To measure the tension force of an anchor, the load meter shown in Fig.12 is generally mounted on the anchor head and fixed, so a hydraulic jack is required to do the work. However, it was confirmed that the steel of existing anchors on the slope was corroded and breakage of steel when tension was applied with a hydraulic jack to install the load meter became a concern. The slope was very steep to work on, and with a limited construction period, there was a need to indicate a method for measuring the tension of existing anchors easily and quickly.

The tension of existing anchors is measured for a short period from the installation of additional anchors to the start of unloading existing anchors. In addition, the tension of existing anchors is measured to confirm the effect the construction of additional anchors has, and is not intended for getting precise measurements. Therefore, considering the degree of corrosion and tension of the existing anchor, a simple method for measuring the tension force was studied where a strain gauge is attached to the nut, on which the tension force of the anchor acts, and the influence of the changes in the tension force is estimated from the strain change. Before measuring the tension by attaching a strain gauge to the nut that fixes the existing anchor, as shown in Fig.13, the characteristics of strain change during loading and unloading were determined in a laboratory test by attaching a strain gauge to a nut of the same standard as the nut that fixes the anchor in the field. The test method is described below.

\section{a) Test method}

Existing anchors constructed on the slope are D26- and D32-type anchors, which are fully threaded PC steel bar-types, shown in Table 2 and Fig. $14^{11)}$. There are two types of nuts for the fully threaded PC steel bar-type anchors: ordinary-type nuts and grooved-type nuts, and the grooved-type nuts are used at the site. To confirm the difference in the measurement depending on the type of nut, laboratory tests were conducted for both types. Figure 15 shows the laboratory test where a strain gauge is attached to the nut of the fully threaded PC screw bar and loaded with a hydraulic jack. The reference maximum load in the loading was 1.25 times the design anchor force.

\section{b) Strain gauge-type and installation position}

For the D26- and D32-type anchors, KFG-5-120$\mathrm{C} 1^{13)}$ strain gauge with a gauge length of $5 \mathrm{~mm}$, which is generally used when the object to be measured is steel, was used. In addition, when the gauge length is longer, the strain measurement section becomes longer and an average measurement value 


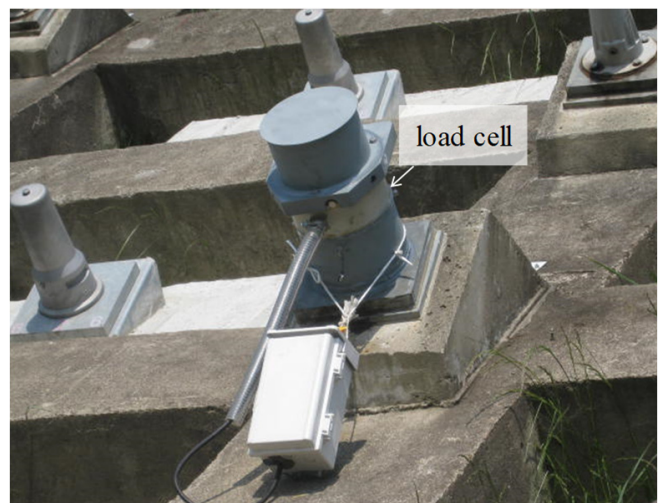

Fig.12 Measurement of tension with load cell.

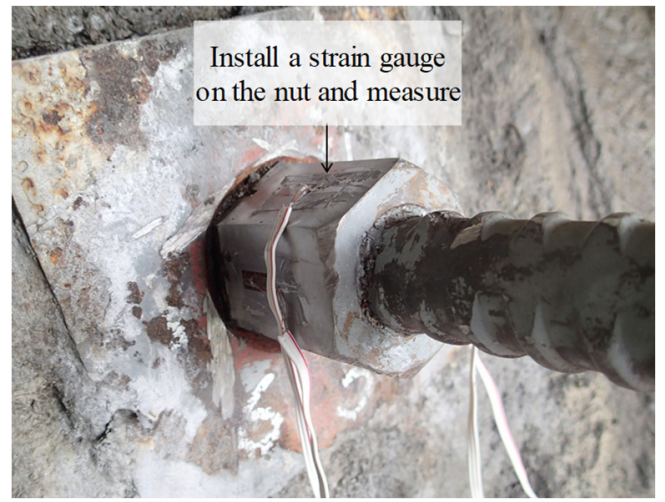

Fig.13 Strain gauge installation status.

may be obtained. Therefore, measurements were also taken for the D26 anchor with a strain gauge of $10 \mathrm{~mm}$ gauge length (KFG-10-120-C1) ${ }^{13)}$ and for the D32 anchor with a strain gauge of $20 \mathrm{~mm}$ gauge length $(\mathrm{KFG}-20-120-\mathrm{C} 1)^{13)}$.

The strain gauge was set at a position $10 \mathrm{~mm}$ away from the plate side, as shown in Fig.14, considering the area of coating at the site. Strain gauges were installed on all six sides of the nut.

\section{c) Test conditions}

In the laboratory test, eight test cases were set up based on the type of fully threaded PC steel bar and the gauge length of the strain gauge, as shown in Table 3. Since the rib of the fully threaded PC steel bar is not placed on the whole circumference, it is assumed that the measured strain values differ depending on whether the rib is facing a side or a corner (diagonal) of the nut as shown in Fig.16. For this reason, under the test conditions shown in Table 3, first the test was conducted with the rib facing a corner (diagonal) of the nut, then the test was conducted with the rib facing a side of the nut.

\section{d) Measurement method of tension of existing an-} chor

Based on the results of the laboratory test, a strain gauge was installed on the existing anchor to evaluate the tension. The procedure for installing the strain gauge is described below.

1. Remove the oil cap from the existing anchor.
Table 2 Nut standards (Material: S45C).

\begin{tabular}{c|c|c|c|c}
\hline $\begin{array}{c}\text { Nickname } \\
\mathrm{D}\end{array}$ & $\begin{array}{c}\text { Distance } \\
\text { to oppo- } \\
\text { site side } \\
\text { B } \\
(\mathrm{mm})\end{array}$ & $\begin{array}{c}\text { Distance } \\
\text { to oppo- } \\
\text { site cor- } \\
\text { ner } \\
\mathrm{C} \\
(\mathrm{mm})\end{array}$ & $\begin{array}{c}\text { Height } \\
\mathrm{H}\end{array}$ & $\begin{array}{c}\text { Diameter } \\
(\mathrm{mm})\end{array}$ \\
\hline $\mathrm{D} 26$ & 50 & 57.7 & 60 & 35 \\
$\mathrm{D} 32$ & 58 & 67.0 & 70 & 42 \\
\hline
\end{tabular}

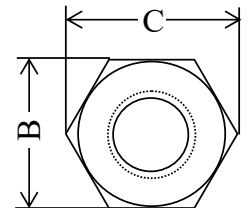

Strain gauge

(a) Ordinary nut

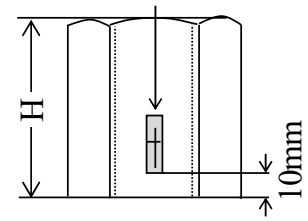

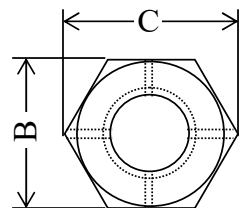

Strain gauge

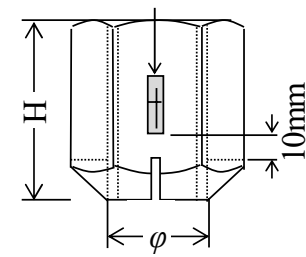

(b) Grooved nut
Fig.14 Nut type and strain gauge installation position ${ }^{11)}$.

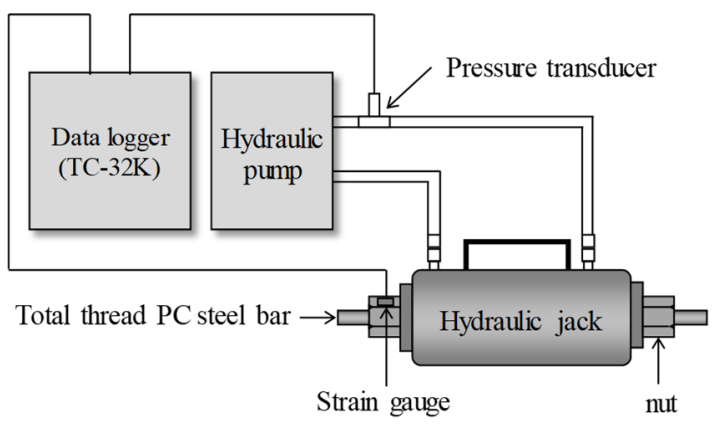

(a) Overview

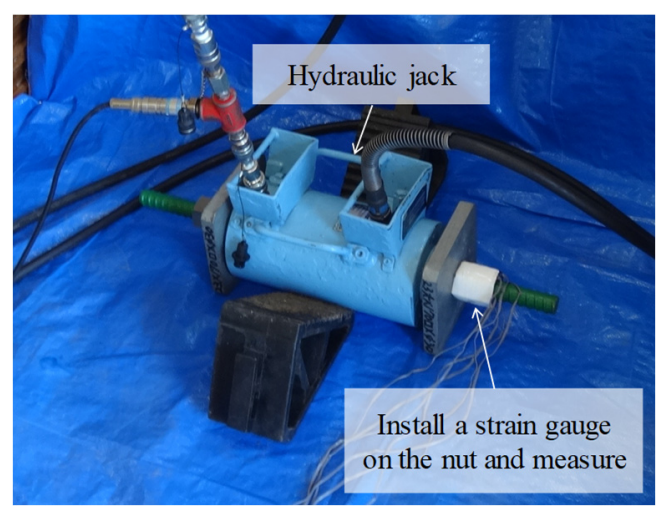

(b) Situation photo

Fig.15 Laboratory test.

2. Remove the rust preventive oil on the nut, polish the nut surface, and remove oil from the polished surface. 
Table 3 Laboratory test case.

\begin{tabular}{|c|c|c|c|c|c|}
\hline CASE & Standard & Nut shape & $\begin{array}{c}\text { Gauge } \\
\text { length } \\
(\mathrm{mm})\end{array}$ & $\begin{array}{c}T_{\mathrm{d}} \\
(\mathrm{kN})\end{array}$ & $\begin{array}{c}T_{\mathrm{p}} \\
(\mathrm{kN})\end{array}$ \\
\hline 1 & D26 & Ordinary & 5 & 316.1 & 400 \\
\hline 2 & D26 & Ordinary & 10 & 316.1 & 400 \\
\hline 3 & D26 & With groove & 5 & 316.1 & 400 \\
\hline 4 & D26 & With groove & 10 & 316.1 & 400 \\
\hline 5 & D32 & Ordinary & 5 & 374.1 & 470 \\
\hline 6 & D32 & Ordinary & 20 & 374.1 & 470 \\
\hline 7 & D32 & With groove & 5 & 374.1 & 470 \\
\hline 8 & D32 & With groove & 20 & 374.1 & 470 \\
\hline
\end{tabular}

$※$ Each No. is tested with rib facing the diagonal of the nut and the side of the nut.

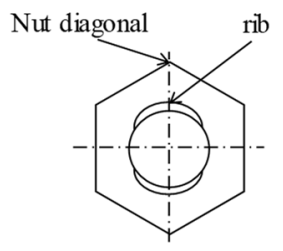

(a) Rib facing diagonal of the nut

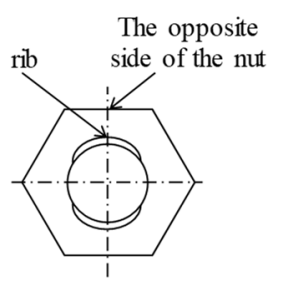

(b) Ribs facing side of of nut
Fig.16 Positional relationship between rib and nut ${ }^{11)}$.

3. Affix the strain gauge to the nut. Also install a thermocouple (T-G-0.65) ${ }^{14)}$ on the existing anchor to evaluate the effect of changes in the outside air temperature on the strain gauge measurements.

4. Drill a hole on the removed oil cap to allow the strain gauge lead wire to go through the cap and out.

5. Connect the strain gauge lead wire to the switch box (CSW-5A) ${ }^{14)}$, as shown in Fig.17(a), and record the strain with the data logger $(\mathrm{TC}-32 \mathrm{~K})^{14)}$.

\section{(2) Measuring method of tension of additional an- chor}

As shown in Fig.17(b), the tension of additional anchors was measured by installing a compression center hall-type load meter (KTK-NA) ${ }^{14)}$ manufactured by Tokyo Sokki Kenkyujo Co., Ltd., and connecting it to a gauge strain data recording device (OSNET NetLG-401) ${ }^{15)}$ made by OSASI Technos.

\section{EXAMINATION AND CONSIDERA- TIONS}

\section{(1) State of existing anchors}

In the "Ground Anchor Maintenance Manual" (hereinafter Maintenance Management Manual) $^{16)}$ jointly compiled by the Civil Engineering Research Institute and the Japan Anchor Association, the

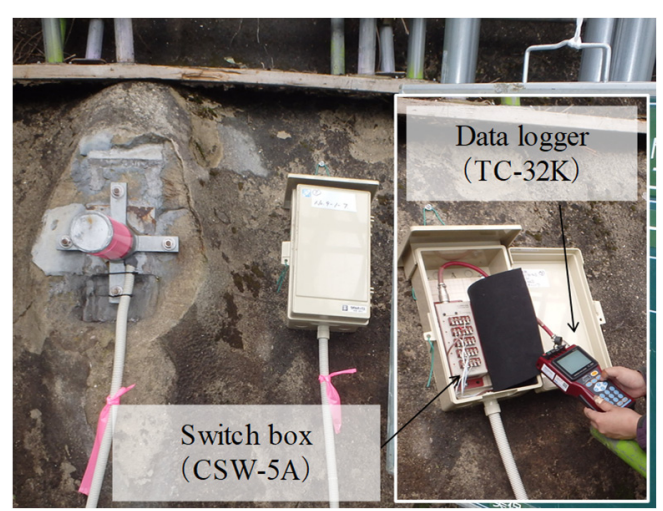

(a) Existing anchor

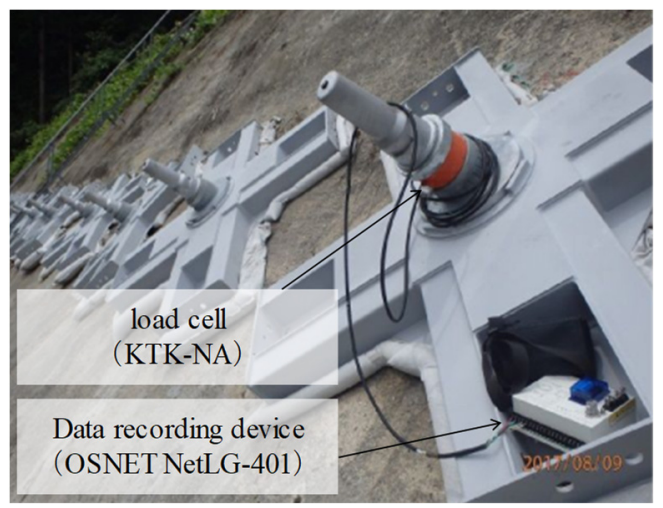

(b) Additional anchor

Fig.17 Measurement of anchor tension.

"Judgments" indicated in Table 4 were made according to the degree of residual tensile force. When the residual tensile force is $80 \%$ or more of the tension force at the time of establishment and less than the design anchor force, it is defined as "A: healthy.", When the tension force is lower than this, the range is defined as between $\mathrm{B}$ and $\mathrm{D}$, and when the tension force is higher, this range is defined as between $\mathrm{B}$ and E. Table 5 shows the lift-off test results for existing anchors, and the residual tensile force ratio $R_{\mathrm{td}}$ is between $33.5 \%$ and $100.0 \%$. When the existing anchors were evaluated according to the maintenance manual, most of them were classified as "A: healthy" or "B: follow-up."

Anchor No.8-1-15 was broken, but if the anchor broke due to slope deformation, it would be considered that the tension of existing anchors tended to increase overall. The residual tensile force $R_{\mathrm{td}}$ of anchor No.8-1-14, located next to the fractured anchor, was $94.6 \%$, and no increase in tension due to the fracture was observed. The average tensile force residual ratio $R_{\mathrm{td}}$ was $79.0 \%$, indicating that the tension was maintained relatively well. From this, it can be inferred that the fracture of the existing anchor was caused by corrosion and other factors and was local, and there had been no significant landslide activity on the slope itself since construction. 
Table 4 Estimated residual tensile force ${ }^{16)}$

\begin{tabular}{c|c|c}
\hline $\begin{array}{c}\text { Range of } \\
\text { residual } \\
\text { tensile force }\end{array}$ & Judgment & Status \\
\hline $0.9 T_{\mathrm{ys}}$ & $\mathrm{E}$ & May break \\
$1.1 T_{\mathrm{a}}$ & $\mathrm{D}$ & Risk of danger \\
$T_{\mathrm{a}}$ & $\mathrm{C}$ & Exceeds allowable value \\
$T_{\mathrm{d}}$ & $\mathrm{B}$ & \\
$P_{\mathrm{t}}$ & $\mathrm{A}$ & healthy \\
$0.8 P_{\mathrm{t}}$ & $\mathrm{A}$ & healthy \\
$0.5 P_{\mathrm{t}}$ & $\mathrm{B}$ & \\
$0.1 P_{\mathrm{t}}$ & $\mathrm{C}$ & Function is greatly degraded \\
\hline
\end{tabular}

Table 5 Lift-off test results for existing anchors.

\begin{tabular}{c|c|c|c|c}
\hline No. & $\begin{array}{c}T_{\mathrm{d}} \\
(\mathrm{kN})\end{array}$ & $\begin{array}{c}P_{\mathrm{e}} \\
(\mathrm{kN})\end{array}$ & $\begin{array}{c}R_{\mathrm{td}} \\
(\%)\end{array}$ & Evaluation $^{\text {note }}$ \\
\hline $5-1-3$ & 374.1 & 259.0 & 69.2 & $\mathrm{~B}$ \\
$5-1-14$ & 374.1 & 313.0 & 83.7 & $\mathrm{~A}$ \\
$5-1-25$ & 374.1 & 248.0 & 66.3 & $\mathrm{~B}$ \\
$6-1-6$ & 374.1 & 337.0 & 90.1 & $\mathrm{~A}$ \\
$6-1-17$ & 374.1 & 374.0 & 100.0 & $\mathrm{~B}$ \\
$7-1-9$ & 374.1 & 295.0 & 78.9 & $\mathrm{~B}$ \\
$7-1-20$ & 374.1 & 315.0 & 84.2 & $\mathrm{~A}$ \\
$8-1-5$ & 374.1 & 374.0 & 100.0 & $\mathrm{~B}$ \\
$8-1-14$ & 374.1 & 354.0 & 94.6 & $\mathrm{~A}$ \\
$8-1-20$ & 374.1 & 255.0 & 68.2 & $\mathrm{~B}$ \\
$9-1-7$ & 374.1 & 349.0 & 93.3 & $\mathrm{~A}$ \\
$9-1-15$ & 374.1 & 254.0 & 67.9 & $\mathrm{~B}$ \\
$10-1-10$ & 316.1 & 106.0 & 33.5 & $\mathrm{C}$ \\
$11-1-4$ & 316.1 & 242.0 & 76.6 & $\mathrm{~B}$ \\
\hline
\end{tabular}

Note: $P_{\mathrm{t}}=T_{\mathrm{d}}$ was evaluated because the tension at establishment was unknown.

\section{(2) Relationship between strain measurement and tension}

A method to measure the changes in the tension during the construction of additional anchors and unloading the tension of existing anchors was examined. This was done by fixing a strain gauge to the nut that fixes the existing anchor. In this study, the characteristics of the strain change in the nut accompanying the change in tension was confirmed by laboratory tests.

Figure 18 shows the relationship between the measured strain and the tension at gauge position 2, when the rib position is facing diagonal of the nut, (CASE2) as an example of measurements taken in the laboratory test. In the first cycle, the incline of the graph differs between the loading process (between $\mathrm{O}$ and $\mathrm{A}$ ) and the unloading process (between $\mathrm{A}$ and

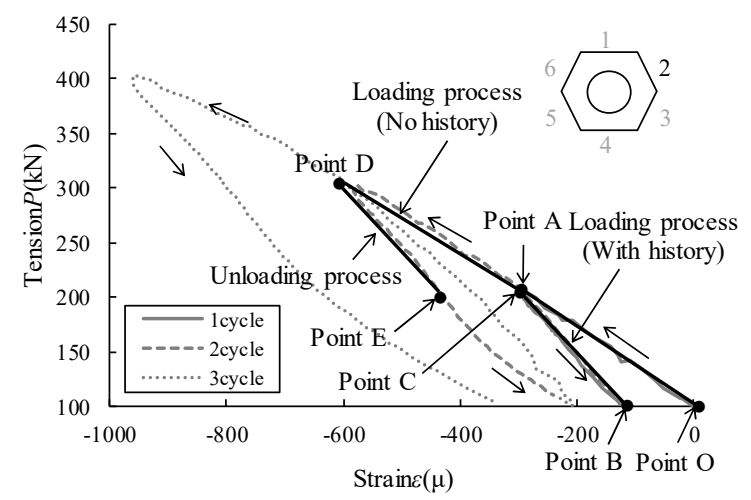

(CASE2, Rib position: Nut diagonal, Gauge position: 2)

Fig.18 Example of measurement results.

B). This is caused by a slight distortion that occurred at the beginning of loading and after the completion of unloading. In the second cycle, the loading process, which is for loads below the maximum test load (between $B$ and C), shows an incline close to that of the first cycle unloading process (between $\mathrm{A}$ and $\mathrm{B}$ ), but when loads more than the maximum test load (between $\mathrm{C}$ and D) are loaded, the incline is close to the loading process (between $\mathrm{O}$ and $\mathrm{A}$ ) in the first cycle. In the unloading process (between $\mathrm{D}$ and $\mathrm{E}$ ), an incline close to the unloading process in the first cycle (between A and B) is observed. This tendency was also observed in other measurements. Therefore, the tension of the existing anchor was estimated by obtaining the approximate linear equation of the section shown in Table 6 from the relationship between the measured strain value and the tension and calculating the calibration coefficient $\alpha$, shown in Table 7, using Equation (1) and Equation (2).

$$
P_{e}^{\prime}=P_{e}+\Delta P
$$

where $P_{e}^{\prime}$ : Estimated residual tensile force $(\mathrm{kN})$

$P_{e}$ : Initial value of residual tensile force $(\mathrm{kN})$

$\Delta P$ : Estimated amount of change in tension due to strain output value of nut $(\mathrm{kN})$

$$
\Delta P=\alpha \cdot \varepsilon
$$

where $\alpha$ :Calibration factor

$\varepsilon$ : Nut strain output value (measured value)

As an example, a method for estimating the tension from the measured strain of an existing anchor is described. This method assumes that the initial value $P_{\mathrm{e}}$ of tension is $300 \mathrm{kN}$ for a fully threaded PC steel rod anchor (D26) and uses the values set as the calibration factor shown in Table 7. When strain $\varepsilon$ changes to the plus side by $100 \mu$, because the estimated value $\Delta P$ of tension change from Equation (2) is $-60 \mathrm{kN}$ (= $0.60 \times-100)$, we can estimate that the tension force $P_{\mathrm{e}}$ ' is $240 \mathrm{kN}$ from Equation (1). On the other hand, when the strain $\varepsilon$ changes to the minus side by $100 \mu$, 
Table 6 Calibration coefficient calculation interval.

\begin{tabular}{c|c|c|c}
\hline Standard & $\begin{array}{c}\text { Loading } \\
\text { process } \\
\text { (With history) }\end{array}$ & $\begin{array}{c}\text { Loading } \\
\text { process } \\
\text { (No history) }\end{array}$ & $\begin{array}{c}\text { Unloading } \\
\text { process }\end{array}$ \\
\hline $\mathrm{D} 26$ & $100 \mathrm{kN} \rightarrow 200 \mathrm{kN}$ & $200 \mathrm{kN} \rightarrow 300 \mathrm{kN}$ & $300 \mathrm{kN} \rightarrow 200 \mathrm{kN}$ \\
$\mathrm{D} 32$ & $200 \mathrm{kN} \rightarrow 300 \mathrm{kN}$ & $300 \mathrm{kN} \rightarrow 400 \mathrm{kN}$ & $400 \mathrm{kN} \rightarrow 300 \mathrm{kN}$ \\
\hline
\end{tabular}

Table 7 Calibration coefficient setting value.

(CASE2, rib position: nut diagonal, gauge position: 2)

\begin{tabular}{l|c}
\hline \multicolumn{1}{c|}{ Item } & $\begin{array}{c}\text { Calibration } \\
\text { factor } \alpha\end{array}$ \\
\hline $\begin{array}{l}\text { Loading process (With history) } \\
\text { Approximate linear formula between } \mathrm{BC}:\end{array}$ & -0.60 \\
$P=-0.60 \varepsilon+27.63$ & \\
\hline $\begin{array}{l}\text { Loading process (No history) } \\
\text { Approximate linear formula between } \mathrm{CD}:\end{array}$ & -0.34 \\
$P=-0.34 \varepsilon+108.19$ & \\
\hline $\begin{array}{l}\text { Unloading process } \\
\text { Approximate linear formula between } \mathrm{DE}:\end{array}$ & -0.60 \\
$P=-0.60 \varepsilon-52.69$ & \\
\hline
\end{tabular}

※ Initial value of residual tensile force $P_{\mathrm{e}}=300 \mathrm{kN}$

we can estimate that it is $334 \mathrm{kN}$ because $\Delta P$ is approximately $+34 \mathrm{kN}(=0.34 \times+100)$. When the maximum load confirmed for the existing anchor is $330 \mathrm{kN}$, the calibration coefficient $\alpha$ for loads exceeding the test maximum load is used when applying $330 \mathrm{kN}$ or more. Since strain up to $330 \mathrm{kN}$ is $88 \mu$ (= $30 / 0.34)$, it is thought that $12 \mu(=100-88)$ out of $100 \mu$ is generated beyond $330 \mathrm{kN}$. From this value, $\Delta P=7 \mathrm{kN}(=0.60 \times 12)$ is obtained by Equation (2), and the estimated value $P_{\mathrm{e}}$ ' of the existing anchor can be estimated to be $337 \mathrm{kN}(=330+7)$.

Based on these results, for nut-fixed PC steel bar anchors, the tension change in existing anchors, in respect to the initial value, can be roughly estimated by setting the calibration factor in the loading process (with and without history) and unloading process from the results of laboratory tests.

\section{(3) Evaluation of calibration factor}

Table 8 shows the calibration coefficient $\alpha$ of the loading process (with history), loading process (without history), and unloading, based on the relationship between the measured strain values and tension at gauge positions 1 to 6 when the rib position is diagonal of the nut, as in CASE2, and the mean and standard deviations were calculated for each. The standard deviation of the loading process (with history) was 0.05 , and the standard deviation of the loading process (without history) was 0.02 . In the loading process, variations in calibration coefficient $\alpha$ was less for the loading process without history. The standard
Table 8 Calibration coefficient setting value.

\begin{tabular}{c|c|c|c}
\hline $\begin{array}{c}\text { Gauge } \\
\text { position }\end{array}$ & $\begin{array}{c}\text { Loading } \\
\text { process } \\
\text { (With history) }\end{array}$ & $\begin{array}{c}\text { Loading } \\
\text { process } \\
\text { (No history) }\end{array}$ & $\begin{array}{c}\text { Unloading } \\
\text { process }\end{array}$ \\
\hline 1 & -0.47 & -0.32 & -0.51 \\
2 & -0.60 & -0.34 & -0.60 \\
3 & -0.60 & -0.34 & -0.59 \\
4 & -0.50 & -0.33 & -0.54 \\
5 & -0.53 & -0.29 & -0.48 \\
6 & -0.50 & -0.35 & -0.46 \\
\hline average & -0.53 & $-0 . .33$ & -0.53 \\
standard & & & \\
deviation & 0.05 & 0.02 & 0.05 \\
\hline
\end{tabular}

deviation of the unloading process was 0.05 , which was similar to the loading process (with history). Using this method, the standard deviation was obtained for each test case, and the variation in the calibration coefficient $\alpha$ was evaluated.

Figure 19 is a graph of the standard deviation of the calibration coefficient $\alpha$ for each test case. The standard deviation tends to be larger for grooved nuts than for ordinary nuts. As shown in Fig.14 (b), the grooved nut has a tapered shape where it is in contact with the anchor plate and has a $2 \mathrm{~mm}$-wide groove in the center. With a grooved nut, it is possible that the effects of these elements may be combined when strain is measured. On the other hand, most of the strain in the axial direction of ordinary nuts is thought to capture the compressive strain acting on the nut, and there is a possibility that the variation in measured values of the grooved nuts was larger than that of the ordinary nut because of this.

In the comparison between when the rib is facing the side and when it is facing the corner of the nut, no clear difference was found between the two. When the gauge length is the same, the standard deviation tends to be larger when the nut diameter is larger. This is because the screw spacing increases as the nut diameter increases, and the positional relationship between the strain gauge and the jaggedness of the screw could have affected deviation. Therefore, a longer gauge length may lessen variations in strain measurements. In both the loading and unloading processes, even in the same test case, the standard deviation tends to be larger when the gauge length is $5 \mathrm{~mm}$ compared with when it is $10 \mathrm{~mm}$ and $20 \mathrm{~mm}$.

Based on the results of such laboratory tests, strain was measured on-site as follows;

1. Gauge length $10 \mathrm{~mm}$ was used for D26, gauge length $20 \mathrm{~mm}$ was used for D32.

2. Strain gauges could be attached to a pair of faces, but they were attached to four faces because of possible measurement problems due to scratches 

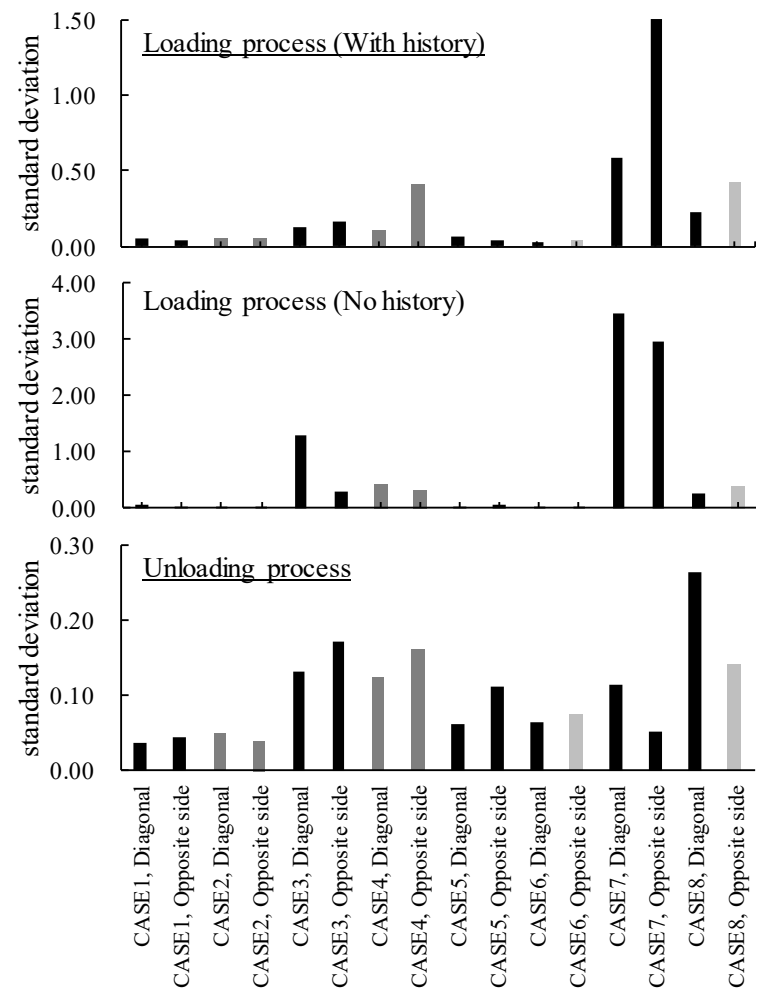

Black : Gauge length $5 \mathrm{~mm}$

Dark gray : Gauge length $10 \mathrm{~mm}$

Light gray : Gauge length $20 \mathrm{~mm}$

Fig.19 Standard deviation of calibration coefficient $\alpha$ for each test case.

or dents on the nut surface. The measured value of strain was evaluated using the average value of the four faces.

3. The calibration coefficient used for estimating the tension was the average value of the calibration coefficients obtained in laboratory tests for when the rib was facing the side or the corner of the nut.

\section{(4) Strain temperature correction}

Figure 20 shows the changes in measured values of the strain gauge and thermocouple attached to the nut of existing anchor No.5-1-3 between 9:30 AM on May 12, 2017 and 9:30 AM on May 16, 2017. The range of fluctuation in the measured values of the strain is about $4 \mu$, and the strain fluctuates along with the changes in the outside temperature of about $50 \mathrm{C}$. Here, a correction is made to eliminate the influence of outside temperature from the measured strain value. Figure 21 shows the relationship between the measured strain values and outside temperature. The coefficient of determination $R^{2}$ obtained from the relationship between the measured strain $\varepsilon$ and the outside temperature $T$ is 0.92 , indicating a high correlation. The relationship between the two can be shown by performing a regression analysis with Equation (3).

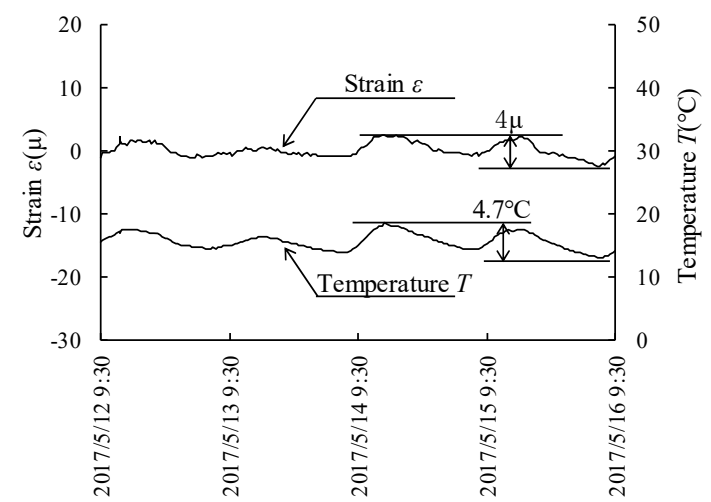

Fig.20 Measurement of anchor tension (No.5-1-3).

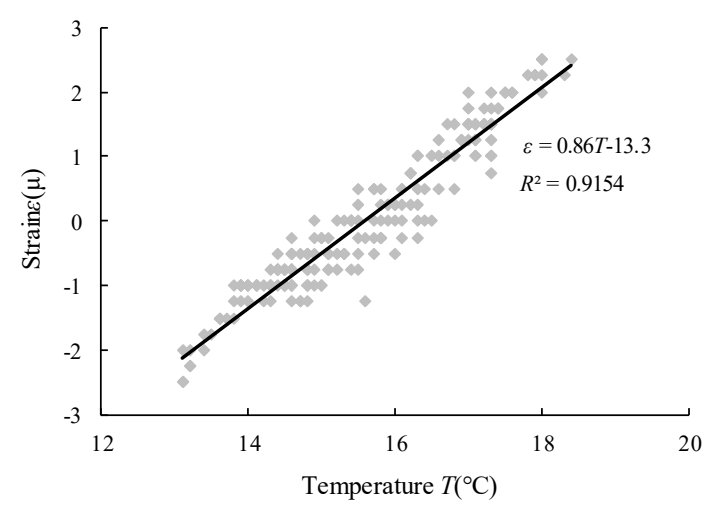

Fig.21 Relationship between measured strain value and outside air temperature (No.5-1-3).

$$
\varepsilon=a \cdot T+b
$$

where

$\varepsilon$ : Strain measurement

$T$ : Outside temperature

$a$ : The incline of the approximate line

$b$ : Approximate straight line intercept

Figure 22 shows the measured strain value and the changes in the outside air temperature when correction is made by setting the strain at the start of measurement at zero by subtracting $\varepsilon_{0}{ }^{\prime}$ from Equation (4).

$$
\varepsilon^{\prime}=\varepsilon-a \cdot T-\varepsilon_{0}^{\prime}
$$

where $\quad \varepsilon^{\prime}$ : Measured value of strain after temperature compensation

$\varepsilon_{0}^{\prime}$ : Strain measurement at the start of measurement

The fluctuation range of the measured strain after temperature correction is as small as $0.8 \mu$. Figure 23 shows the tension of anchor estimated using the temperature-corrected strain and the calibration coefficient $\alpha$ obtained in the laboratory test. The initial value of tension was obtained by the lift-off test. As a result, the fluctuation range of tension was about $2.2 \mathrm{kN}$ when the temperature change was about $50 \mathrm{C}$.

\section{(5) Changes in tension of existing anchors}

The construction of additional anchors and tension 
establishment were carried out sequentially from the 11th stage to the lower stage by installing temporary scaffolding up to the top 11th stage. Figure 24 shows the changes in the tension of existing anchors and the outside air temperature caused by the construction and tension establishment of additional anchors shown in Table 9. Although the existing anchors are temperature-corrected, the tension tends to change in response to changes in the outside air temperature. The tension's range of increase/decrease varies with the anchor, which may be due to differences in sunshine conditions or the precision of strain gauge installation.

For each anchor, a change point (point X) where the change in the outside air temperature becomes larger than before is seen, and the change point appears earlier, the higher the anchor is. When additional anchors were constructed for a stage, in the period shown in Table 9, the scaffolds were dismantled and moved and rebuilt at a lower stage for constructing anchors. Immediately after the start of observation, existing anchors were located under the scaffolds, in the shade, but as the construction of additional anchors progressed, the scaffolds were dismantled and moved to a lower stage, so that the existing anchors and data logger became exposed to direct sunlight, and it is possible that the influence of outside temperature became higher. After reaching change point $\mathrm{X}$, it was found that the fluctuation in tension tended to become larger.

There were two existing anchors where the tension changed significantly: No.10-1-10 on the 10th stage and No.5-1-3 on the 5th stage. In addition, with anchor No.8-1-14 on the 8th stage, there was a tendency for the tension force to fluctuate more with changes in the outside air temperature.

With anchor No.10-1-10, the tension decreased with the tension establishment of additional anchors, carried out from May 30 to May 31, 2017. The No.10-1-10 cracked at the mortar sprayed surface of the pressure plate when tension was fixed on May 30 and subsided. At this time, the tension decreased by about $10 \mathrm{kN}$ between 9:30 AM and 10:30 AM on May 30 . In addition, the fluctuation range of the tension force influenced by outside temperature was about $8 \mathrm{kN}$ at maximum before deformation, but it greatly increased to about $35 \mathrm{kN}$ after the deformation. However, no significant decrease was found in the overall trend after the deformation.

In previous researches ${ }^{17}$, 18), 19), the tension of anchors installed on pressure-receiving structures with different stiffnesses was measured with a strain gauge-type load meter. The results confirm that the fluctuation width tends to be narrower when the stiffness of the pressure-receiving structure is higher. From this, we can assume that the tension force of the

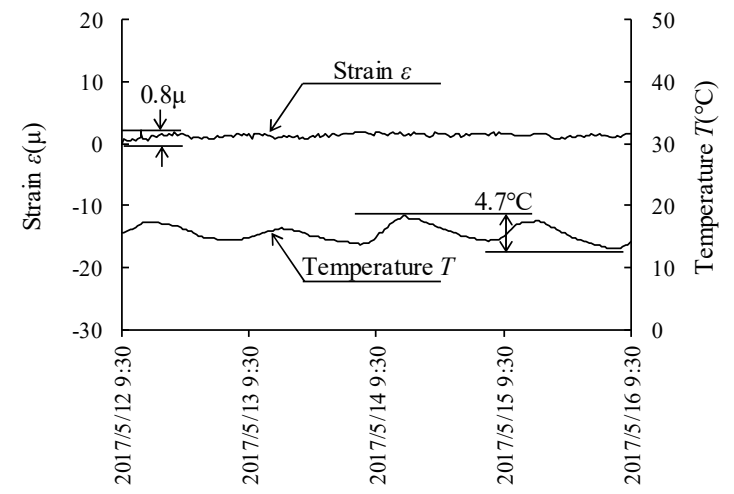

Fig.22 Corrected distortion measurement value and change in outside air temperature (No.5-1-3).

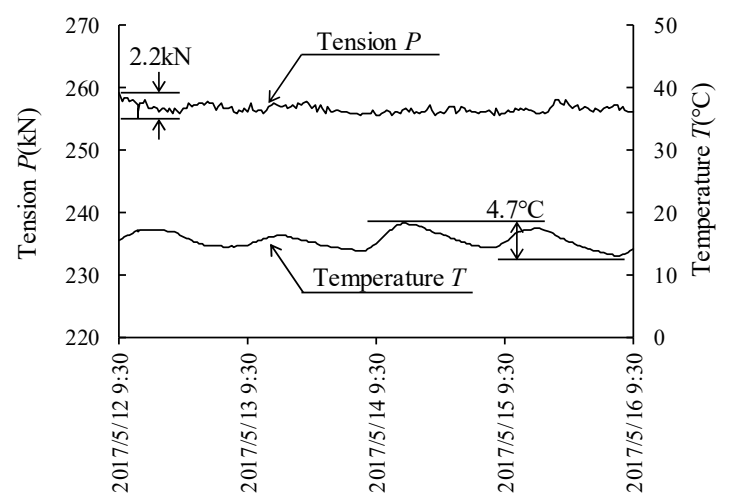

Fig.23 Changes in tension and outside temperature (No.5-1-3).

anchor becomes more sensitive to changes in the outside air temperature when the pressure-receiving structure of the anchor deforms because of failure in the surface layer, and fluctuations in the tension force become larger. Therefore, it was assumed that the cause of the decrease in the tension of No.10-1-10 anchor was not the movement of the slope itself, but the deformation of the slope protection work.

With No.8-1-14 anchor, the tension force's range of fluctuation was about several $\mathrm{kN}$ before additional anchors were constructed, but gradually increased after anchors at the 8th stage were tensioned from June 23 to June 26 , and increased to about $30 \mathrm{kN}$ after anchors at the 6th stage were tensioned. Since fluctuations in the tension increased after reaching point $\mathrm{X}$, when changes in the outside air temperature increased, the change in sunlight conditions due to the dismantling of the scaffolding may have affected the increase/decrease.

No.5-1-3 showed a tendency for tension to increase from June 30 to July 14, when the tension of the additional anchors was fixed from the top row. However, after additional anchors were constructed on the 5 th stage, from July 8 to July 15 , the tension decreased and tended to converge thereafter. The tensions of No.5-1-14 and No.5-1-25 also tended to slightly decrease with the construction of additional anchors. The maximum increase or decrease in 

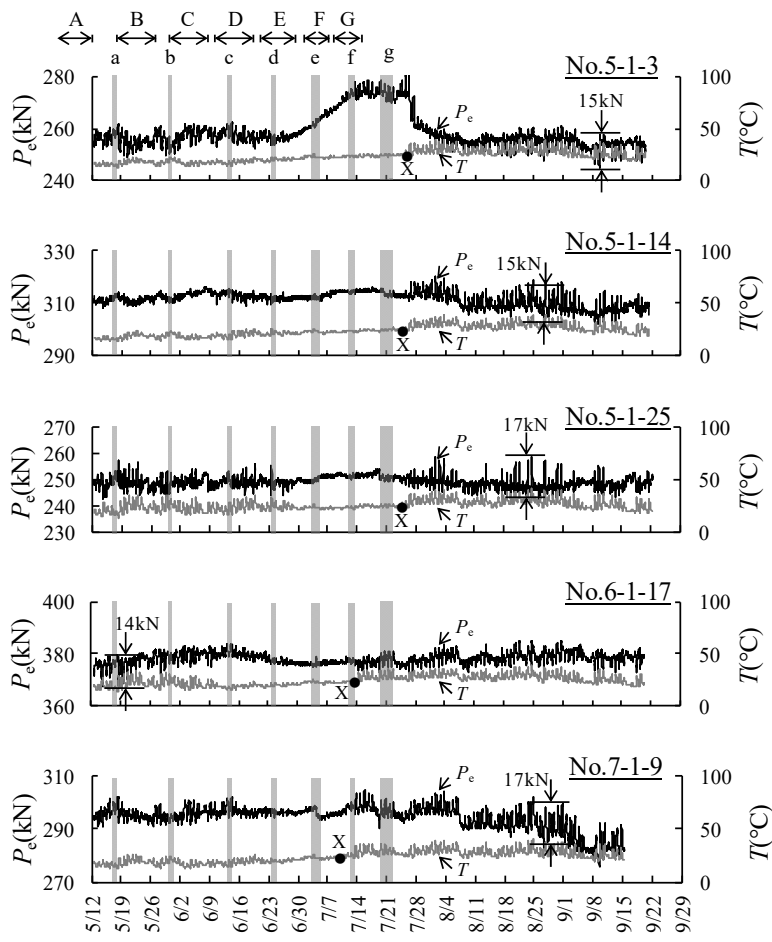
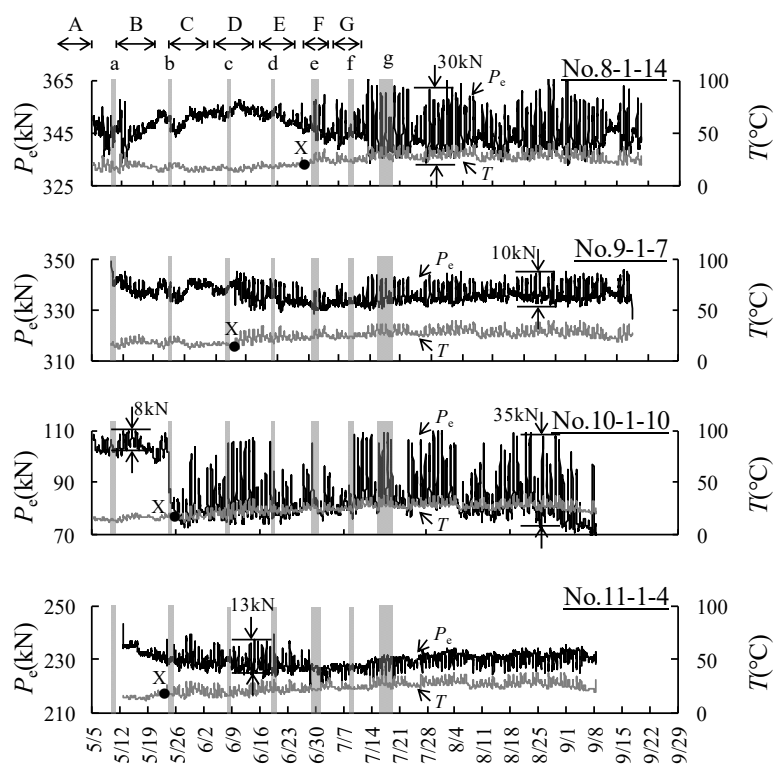

Fig.24 Changes in tension of existing anchors.

tension with temperature change was about $15 \mathrm{kN}$. Unlike No.10-1-10, where the tension decreased due to the deformation of slope protection work, no significant increase or decrease in the tension was observed due to changes in the outside air temperature after the tension changed. From the measurement results, it can be assumed that the installation of additional anchors from the top of the slope affected existing anchor at the bottom and that this impact was reduced when the construction of the additional anchors to the bottom was completed. Based on this, it was evaluated that the cause of the temporary increase in tension of No.5-1-3 was due to the behavior of the slope itself accompanying the construction of additional anchors.

From the measurement results, we can see that although existing anchors responded temporarily when additional anchors were tension-fixed, the tension became constant and did not increase after that. In addition, the tension fluctuated in the range of about maximum $40 \mathrm{kN}$ with changes in the outside air temperature. However, it was possible to fully evaluate the tendency in the tension change in existing anchors caused by constructing additional anchors. After confirming this situation, unloading of existing anchors was judged following No.5 and No.6 in the Fig.11 flowchart, and unloading was carried out from September 8 to 22. Table $\mathbf{1 0}$ summarizes the changes in the tension of existing anchors when the existing anchors were unloaded sequentially from the top down. "Average tension" is the average of tension measured between August 1 and September 7 when the tensioning of additional anchors was completed and changes
Table 9 Additional anchor construction and tension fixing.

\begin{tabular}{c|cccc|cccc}
\hline Stage & \multicolumn{3}{|c|}{ Construction period } & \multicolumn{4}{c}{$\begin{array}{c}\text { Tension establishment } \\
\text { period }\end{array}$} \\
\hline 11 & A. & $5 / 9$ & - & $5 / 12$ & a. & $5 / 16$ & - & $5 / 17$ \\
10 & B. & $5 / 17$ & - & $5 / 27$ & b. & $5 / 30$ & - & $5 / 31$ \\
9 & C. & $5 / 30$ & - & $6 / 8$ & c. & $6 / 13$ & - & $6 / 14$ \\
8 & D. & $6 / 10$ & - & $6 / 19$ & d. & $6 / 23$ & - & $6 / 26$ \\
7 & E. & $6 / 21$ & - & $6 / 29$ & e. & $7 / 3$ & - & $7 / 5$ \\
6 & F. & $7 / 1$ & - & $7 / 7$ & f. & $7 / 12$ & - & $7 / 14$ \\
5 & G. & $7 / 8$ & - & $7 / 15$ & g. & $7 / 19$ & - & $7 / 22$ \\
\hline
\end{tabular}

in the tension of existing anchors had converged. "Tension" is the average of the daily measurements, and "Rate" of change is the ratio of the tension to the average tension. With No.10-1-10, the tension after unloading decreased by about $7 \%$ to $15 \%$. It may be said that the measured values vary more than others because the anchor was affected more by outside air temperature because of the deformation of the slope protection works. The rate of change in the tension of existing anchors other than this anchor was about \pm $3 \%$, which shows that the effect of unloading the tension of existing anchors on the tension of other existing anchors is small.

\section{(6) Changes in tension of additional anchors}

Figure 25 shows the changes in tension of eight additional anchors. The vertical axis of the graph shows a value of $\pm 10 \%$, which is a criterion of construction management standards for design anchor force. Looking at the conceptual diagram of the 
Table 10 Impact assessment of existing anchors before and after unloading.

\begin{tabular}{|c|c|c|c|c|c|c|c|c|c|c|c|c|c|c|c|c|c|}
\hline \multirow{3}{*}{ No. } & \multirow{3}{*}{$\begin{array}{c}\text { De- } \\
\text { fault } \\
\text { value } \\
(\mathrm{kN}) \\
\end{array}$} & \multirow{3}{*}{$\begin{array}{c}\text { Average } \\
\text { tension } \\
(\mathrm{kN}) \\
\end{array}$} & \multirow{3}{*}{$\begin{array}{c}\text { Jnloading } \\
\text { date }\end{array}$} & \multicolumn{2}{|c|}{$\begin{array}{r}\text { Unloadin } \\
\text { date } 9 / 8\end{array}$} & \multicolumn{2}{|c|}{$\begin{array}{c}\text { Unloading } \\
\text { date } 9 / 9\end{array}$} & \multicolumn{2}{|c|}{$\begin{array}{c}\text { Unloading } \\
\text { date } 9 / 11\end{array}$} & \multicolumn{2}{|c|}{$\begin{array}{l}\text { Unloading } \\
\text { date } 9 / 13\end{array}$} & \multicolumn{2}{|c|}{$\begin{array}{l}\text { Unloading } \\
\text { date } 9 / 15\end{array}$} & \multicolumn{2}{|c|}{$\begin{array}{c}\text { Unloading } \\
\text { date } 9 / 20\end{array}$} & \multicolumn{2}{|c|}{$\begin{array}{l}\text { Unloading } \\
\text { date } / 9 / 21\end{array}$} \\
\hline & & & & Tensio & $\mathrm{Ra}$ & Tension & Rate & Tension & Rat & Tension & Rate & Tension & Rate & Tension & Rate & ensio & Rate \\
\hline & & & & $(\mathrm{kN})$ & $(\%)$ & $(\mathrm{kN})$ & $(\%)$ & $(\mathrm{kN})$ & $(\%)$ & $(\mathrm{kN})$ & $(\%)$ & $(\mathrm{kN})$ & $(\%)$ & $(\mathrm{kN})$ & $(\%)$ & $(\mathrm{kN})$ & $(\%)$ \\
\hline & 2.0 & 231.2 & $9 / 8$ & & - & & - & & & & & & - & & - & & - \\
\hline & 6.0 & & & & -7.4 & & -14.6 & & - & - & - & - & - & - & - & - & - \\
\hline $1-7$ & 349.0 & 336.6 & & 37.3 & 0.2 & & 0.4 & & 0.0 & & - & 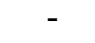 & - & - & - & - & - \\
\hline $8-1-14$ & 354.0 & 344.6 & 13 & 347.8 & 0.9 & 346.8 & 0.7 & 344.5 & 0.0 & 45.8 & 0.4 & - & - & - & - & - & - \\
\hline $1-9$ & 295.0 & 2 & 15 & 2.1 & -3.4 & & -3.1 & 283.8 & -2.9 & 284.4 & -2.6 & & -1.9 & - & - & - & - \\
\hline $1-17$ & 374.0 & 379.1 & $/ 20$ & 378.1 & -0.3 & & -0.1 & 378.7 & -0.1 & & -0.4 & & -0.1 & 378.8 & -0.1 & - & - \\
\hline & 259.0 & & & 251.6 & -1.5 & & -1.3 & & -0.6 & & -0.9 & & -0.8 & 254.0 & -0.5 & - & - \\
\hline $5-1-14$ & 313.0 & & $9 / 21$ & 306.3 & -1.3 & 306.5 & -1.2 & 307.7 & -0.8 & 307.9 & -0.8 & 308.1 & -0.7 & 309.0 & -0.4 & 312.3 & 0.6 \\
\hline $5-1-25$ & 248.0 & 248.5 & $9 / 22$ & 248.5 & 0.0 & 248.3 & -0.1 & 248.1 & -0.1 & 247.6 & -0.4 & 247.8 & -0.3 & 249.4 & 0.3 & 249.6 & 0.4 \\
\hline
\end{tabular}

Note 1: Average tension is the average value of tension from August 1 to September 7, 2017.

Note 2: Tension is the average of the daily measurement data.

Note 3: The rate of change is the ratio of tension to average tension.

change in tension over time (Fig.5), the relaxation of the steel, the difference in the subsidence of the ground, and other factors can be considered as factors that cause the tension to vary from anchor to anchor within the range of $\pm 10 \%$ of the design anchor force.

When unloading the tension of existing anchors, there was no clear change in the tension of additional anchors. In addition, observation for about eight months after unloading showed that there is a general tendency for tension to decline in winter (December to February), which may be caused by weather conditions. The maximum change in tension accompanying changes in the outside temperature is approximately $30 \mathrm{kN}$ or less. For the No.11-14 anchor, data from March 10 to April 9 were missing due to damage to the cord connecting the load cell and the data logger, so measurement was resumed after replacing the cord.

Table 11 summarizes the changes in the tension of additional anchors before and after unloading existing anchors, and eight months after unloading. The initial value is the first measurement taken after the fixation of additional anchors and after the effects of relaxation and subsidence of the ground converged. The "Tension before unloading" is the average value of the measurements from the start of measurement to the time before unloading. The "Tension after unloading" is the average value of tension measured from September 23 to 30, 2017. The "Tension after eight months" is the average value of tension measured from May 1 to 31, 2018. The decrease in tension after unloading existing anchors was $-0.2 \%$ at maximum, and no significant change was observed in the tension of additional anchors. In addition, the decrease in tension after eight months was very small at $-1.6 \%$ to $-0.5 \%$, which was considered to be caused by the relaxation of steel.
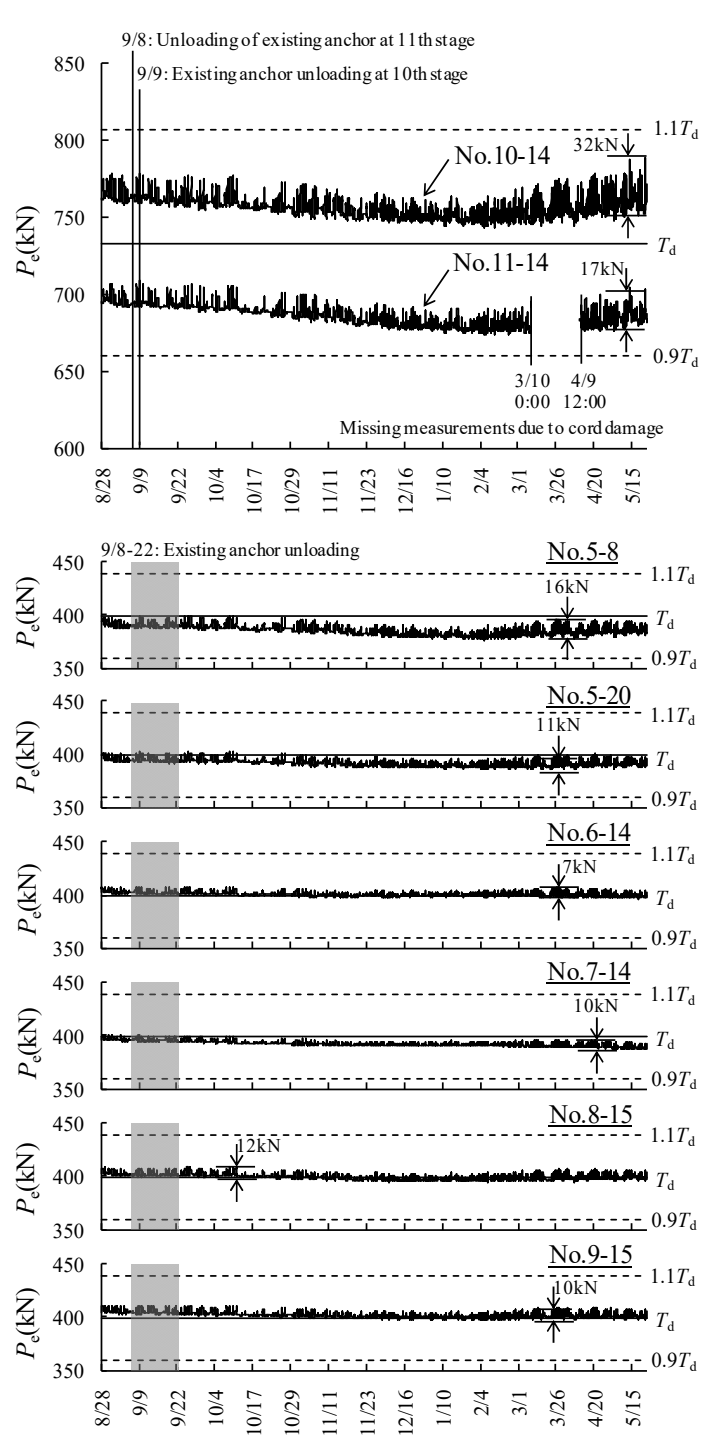

Fig.25 Additional anchor tension change.

(7) Evaluation of tension unloading method for existing anchors

By constructing anchors following the Fig.11 
Table 11 Evaluation of the impact of additional anchor before and after unloading.

\begin{tabular}{ccccccc}
\hline No. & $\begin{array}{c}\text { Default } \\
\text { value } \\
(\mathrm{kN})\end{array}$ & $\begin{array}{c}\text { a) } \\
\text { Tension before } \\
\text { unloading(\%) }\end{array}$ & $\begin{array}{c}\text { Tension after un- } \\
\text { loading(\%) }\end{array}$ & $\begin{array}{c}\text { Tension after } 8 \\
\text { months(\%) }\end{array}$ & $\begin{array}{c}\text { Ratio of b) - a) } \\
\text { to the initial } \\
\text { value(\%) }\end{array}$ & $\begin{array}{c}\text { Ratio of c) - a) } \\
\text { to initial } \\
\text { value(\%) }\end{array}$ \\
\hline $5-8$ & 394.4 & 98.9 & 99.0 & 97.8 & 0.1 & -1.1 \\
$5-20$ & 398.5 & 99.0 & 99.0 & 98.1 & 0.0 & -0.9 \\
$6-14$ & 404.0 & 99.6 & 99.6 & 98.8 & 0.0 & -0.8 \\
$7-14$ & 397.7 & 99.5 & 99.4 & 97.9 & -0.1 & -1.6 \\
$8-15$ & 402.6 & 100.0 & 100.0 & 99.2 & 0.0 & -0.8 \\
$9-15$ & 410.3 & 98.7 & 98.6 & 97.7 & -0.1 & -1.0 \\
$10-14$ & 769.7 & 99.2 & 99.0 & 98.7 & -0.2 & -0.5 \\
\hline $11-14$ & 699.4 & 99.3 & 99.1 & 97.9 & -0.2 & -1.4 \\
\hline
\end{tabular}

Note 1: The initial value is the value at the start of measurement.

Note 2: The tension before unloading is the average value of the measured data from the start of measurement to before unloading.

Note 3: The tension after unloading is the average tension during the period from September 23 to 30, 2017.

Note 4: The tension after eight months is the average tension during the period from May 1 to 31, 2018.

flowchart, it was possible to construct additional anchors and unload the tension of existing anchors without destabilizing the slope. A strain gauge was used to confirm the changes in the tension of the existing anchors, and it was found that the range of fluctuation in the tension caused by changes in the outside air temperature was about $40 \mathrm{kN}$ or less, which was about the same as the range of change in the measured load value of additional anchors. From this, it can be judged that measuring the tension of existing anchors using strain gauges is sufficiently applicable to capture short-term changes associated with the construction of additional anchors and the unloading of existing anchors. Because existing anchors employ a PC steel bar nut anchoring system with a simple anchor head structure, there was a possibility that the changes in the tension force appeared relatively clearly. With regard to this, it is necessary to carry out an analysis on setting the calibration coefficient of other types of anchors by conducting the same type of laboratory test as in this study.

For this study, a slope where the tension force of existing anchors as a whole tended to be lower than the design anchor strength and where there was no noticeable deformation was selected. When unloading tension on a slope where existing anchors are in an overtensed state as a whole, it is assumed that the tension of additional anchors increase at unloading. In such a case, it may be necessary to consider increasing a certain amount of tension for anchoring of additional anchors, which is an issue to be discussed in the future. Also, depending on the slope, the extension of the lower anchors may be shorter than that of the upper anchors, as shown in Fig.26, and the lower the anchor is, the tension tends to increase with a slight slope displacement. In such cases, it is important to consider the order of construction to maintain slope stability, such as constructing additional

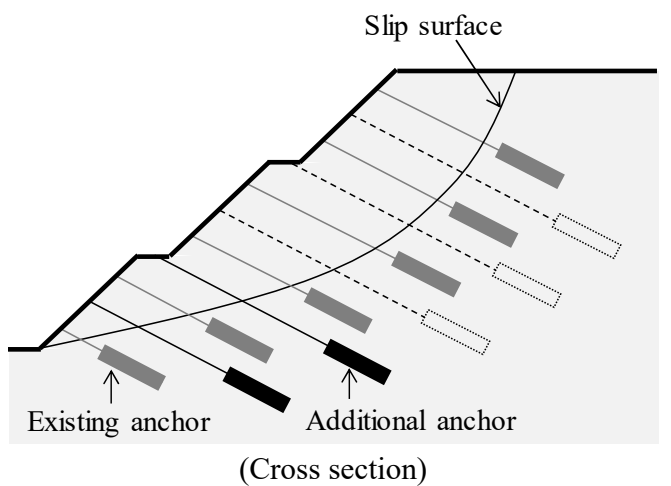

(a) Additional anchor construction (from lower to upper)

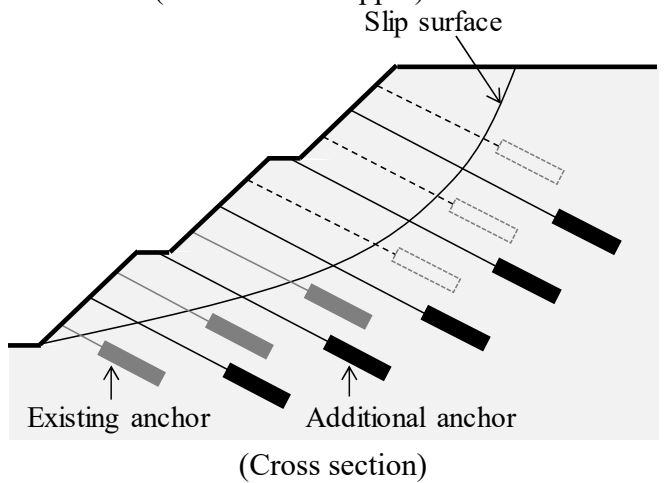

(b) Unloading tension from existing anchors (from top to bottom)

Fig.26 Example of construction sequence considering slope stability.

anchors from the bottom of the slope and up and unloading existing anchors from the top to bottom.

\section{CONCLUSION}

In this paper, the unloading of existing anchors on a slope slated for an expressway renewal project is planned. The effects of unloading existing anchors on the tension of additional anchors are evaluated by 
analyzing the measured tension data of the existing and additional anchors. As a result, the following were clarified,

(1) When it is necessary to unload the tension of existing anchors for the construction of additional anchors as a deterioration countermeasure, quick and appropriate measures can be taken to prevent instability of the slope by also monitoring the changes in the tension of existing anchors.

(2) On this slope, a method in which a strain gauge is attached to the nut that fixes the existing anchor to monitor the tension change during the construction of additional anchors and unloading of existing anchors is examined. In the study, the characteristics in strain change in the nut accompanying the change of tension are confirmed in laboratory tests.

(3) Laboratory tests showed that the inclines of the graphs indicating the relationship between strain and tension differ between the loading and unloading process of tension. In addition, in the loading process, the inclines of the graphs tended to differ in the range below the maximum test load measured, measured up to now, and above the maximum test load.

(4) As for the nut-fixed-type PC steel bar anchors, by setting the calibration coefficient in the loading process (with history and without history) based on the results of laboratory tests, it was possible to roughly estimate changes in tension from the initial tension value of existing anchors.

(5) Laboratory tests showed that PC steel bar anchors show a larger variation in the measured values for grooved nuts than for ordinary nuts. In addition, measurements varied less as the gauge got longer both in the loading and unloading processes even in the same laboratory test case.

(6) From the measurements of strain gauges installed on existing PC steel bar anchors on the slope, measuring tension of existing anchors using strain gauges was judged sufficiently applicable as a method of capturing short-time changes caused by the construction of additional anchors and unloading of existing anchors. Existing anchors were a nut-fixing-type PC steel bar anchors with a simple anchor head structure, so it is possible that changes in tension force appeared relatively clearly.

(7) If there is slope deformation or depending on the tension of existing anchors, additional anchors may be constructed from the bottom of the slope and up, and the tension of the existing anchors may be unloaded from the top of the slope and down. It is important to examine the construction order considering slope stability.

\section{CLOSING REMARKS}

Anchor installation works to counter the deterioration of anchors will increase as expressway renewal works are expected to be carried out nationwide. For this reason, it is necessary to consider reducing the burden on anchor maintenance at the construction stage. In this paper, we studied an expressway slope as an experimental field for the current problem and indicated a concrete procedure for unloading the tension of existing anchors, which is thought to be useful knowledge in carrying out similar construction works. After completing the construction of all additional anchors on the slope, the unloading of existing anchors was judged after confirming the changes in the tension of existing anchors. However, depending on the construction period and site conditions, it may be possible to unload existing anchors as additional anchors are constructed. In the future, we plan to study the design and construction of other cases as the project progresses, and examine methods for tension management of anchors that may be applied in various situations.

\section{REFERENCES}

1) Technical Review Committee on Long-term Conservation and Renewal of Expressway Assets: Report, pp. 1-19, 2014.

2) NEXCO East, NEXCO Central, NEXCO West : Technical Review Committee on Long-term Conservation and Renewal of Expressway Assets (Report), pp. 1-19, 2014.

3) Yokota, Y.: Technology for repairing and reinforcing earthwork structures on expressway (Expressway renewal project), Foundation works, Vol. 45 (10), pp. 14-17, 2017.

4) Fujiwara, Y., Wachi, T., Murakami, T., Fukuda, H., Aso, T. and Sato, M.: Anti-aging efforts of ground anchors in largescale repair projects, Foundation works, Vol. 45 (10), pp. 32-34, 2017.

5) Fujiwara, Y. and Wachi, T.: Problems and countermeasures for aging of ground anchors, The 58th Geotechnical Society Hokkaido Branch Technical Report, pp. 333-336, 2018.

6) Fujiwara, Y. and Sakai, T.: Maintenance of anchor slope focusing on distribution characteristics of residual tensile force of ground anchor, Journal of Japan Society of Civil Engineers C (Geosphere Engineering), Vol. 68, No. 2, pp. 260-273, 2012.

7) Fujiwara, Y. and Sakai, T.: Examination of "point" to "surface" evaluation method for ground anchor soundness, Journal of Japan Society of Civil Engineers C (Geosphere Engineering), Vol. 73, No. 4, pp. 460-474, 2017.

8) Central Nippon Expressway Co., Ltd.: Earthwork Construction Management Guidelines (III. Cut Work), pp. 30-52, 2017.

9) Central Nippon Expressway Co., Ltd .: Design Procedure vol. 1 Earthworks Construction (2. Cutting), pp. 65-79, 2016.

10) Japanese Geotechnical Society: Ground anchor design and construction standards, commentary, pp. 1-211, 2012.

11) Sumitomo Electric Steel Wire Co., Ltd .: Sumitomo Electric PC Steel, pp. 1-23, 2018.

12) SEEE Co., Ltd .: SEEE Ground Anchor Method, Tible Anchor Type A, pp. 2-7, 2008.

13) Kyowa Dengyo Co., Ltd .: General-purpose foil strain 
gauge, pp. 18-25, 2018.

14) Tokyo Sokki Kenkyujo Co., Ltd .: TML General Catalog 2017-2018, pp. 61-130, 2017.

15) OSASHI TECHNOS: OSASI New Product Guide 12, pp. 1, 2003.

16) Public Works Research Institute, Japan Anchor Association: Ground Anchor Maintenance Manual, pp. 74-75, 2008.

17) Fujiwara, Y. and Sakai, T.: Examination on monitoring method of residual tensile force of ground anchor, Journal of Japan Society of Civil Engineers C (Geosphere Engineering), Vol. 67, No. 4, pp. 558-568, 2011.
18) Sakai, T., Tsunekawa, Y., Taguchi, H., Sakaguchi, K., Fujiwara, Y. and Ichihashi, Y.: Maintenance of ground anchor using anchor tension and temperature, Journal of the Japan Landslide Society, Vol. 51, No. 6, pp. 237-242, 2014.

19) Fujiwara, Y., Yokota, S., Sakai, T. and Tsunekawa, Y.: Installing load meter on wedge-fixing-type existing anchors, The 66th Annual Conference of Japan Society of Civil Engineers, pp. 657-658, 2011.

(Received December 18, 2019)

(Accepted March 26, 2020) 